\title{
Assessment of Degradation Equivalent Operating Time for Aircraft Gas Turbine Engines
}

\author{
Ogechukwu Alozie, Yi-Guang Li, Michail Diakostefanis \\ o.alozie@cranfield.ac.uk \\ Cranfield University \\ School of Aerospace, Transport and Manufacturing \\ MK43 OAL, Bedford \\ United Kingdom
}

\section{Xin Wu, Xingchao Shong, Wencheng Ren}

Shenyang Engine Design and Research Institute (SEDRI)

Aircraft Engine Corporation of China (AECC)

China

\section{ABSTRACT}

This paper presents a novel method for quantifying the effect of ambient, environmental and operating conditions on the progression of degradation in aircraft gas turbines based on the measured engine and environmental parameters. The proposed Equivalent Operating Time (EOT) model considers the degradation modes of fouling, erosion, and blade tip wear due to creep strain, and expresses the actual degradation rate over the engine clock time relative to a pre-defined reference condition. In this work, the effects of changing environmental and engine operating conditions on the EOT for the core engine booster compressor and the high-pressure turbine were assessed by performance simulation with an engine model. The application to a single and multiple flight scenarios showed that, compared to the actual engine clock time, the EOT provides a clear description of component degradation, prediction of remaining useful life, and sufficient margin for maintenance action to be planned and performed before functional failure.

Keywords: Gas turbine; Performance; Degradation; Fouling; Erosion; Creep; Equivalent Operating Time; Prognostics; Remaining Useful Life 


\section{NOMENCLATURE}

\begin{tabular}{|c|c|}
\hline CDP & Cloud Droplet Probe \\
\hline d & Diameter $(\mu \mathrm{m})$ \\
\hline $\mathrm{D}$ & Degradation or damage level \\
\hline DEvAC & Duration of Exposure versus Ash Concentration \\
\hline DPA & Design Point Adaptation \\
\hline ECAM & Electronic Centralized Aircraft Monitor \\
\hline Eff & Efficiency health index \\
\hline EOT & Equivalent Operating Time (hours) \\
\hline $\mathrm{FC}$ & Flow Capacity health index \\
\hline GA & Genetic Algorithm \\
\hline HP & High-Pressure \\
\hline I.Fan + LPC & Integrated Inner Fan and Low-Pressure Compressor (Booster) \\
\hline ISA & International Standard Atmosphere \\
\hline LMP & Larson-Miller Parameter \\
\hline LP & Low-Pressure \\
\hline NGV & Nozzle Guide Vane \\
\hline $\mathrm{N}$ & Relative shaft speed (\%) \\
\hline OEM & Original Engine Manufacturer \\
\hline O.Fan & Outer Fan \\
\hline $\mathrm{p}$ & Static pressure (atm) \\
\hline $\mathrm{P}$ & Total pressure (atm) \\
\hline PCASP & Passive Cavity Aerosol Spectrometer Probe \\
\hline PM & Particulate Matter \\
\hline $\mathrm{RH}$ & Relative Humidity \\
\hline RMSE & Root Mean Squared Error \\
\hline RUL & Remaining Useful Life (hours) \\
\hline SFC & Specific Fuel Consumption \\
\hline SLS & Sea Level Static \\
\hline $\mathrm{t}$ & Time / Static temperature $(\mathrm{K})$ \\
\hline $\mathrm{T}$ & Total temperature $(\mathrm{K})$ \\
\hline TET & Turbine Entry Temperature (K) \\
\hline $\mathrm{W}$ & Mass flow rate $(\mathrm{kg} / \mathrm{s})$ \\
\hline
\end{tabular}

\section{Subscripts}

$0, a$

air

corr

C

E

F

FF

$\mathrm{p}$

$r$

ref

Ambient condition

Air property

Corrected to standard inlet temperature and pressure (for mass flow)

Creep strain

Erosion

Fouling

Fuel flow

Particle

Corrected to standard inlet temperature (for rotational speed)

Reference condition 


\subsection{INTRODUCTION}

Although gas turbine engines for aircraft propulsion are designed and manufactured to meet high standards of efficiency, fuel economy, reliability and safety, the nature of their operation exposes them to hostile conditions that adversely impact their performance over time $[1,2]$. These conditions may be caused by factors originating within the engine such as blade tip rubs during transient operation or rotor imbalance leading to excessive seal wears and increased blade tip clearance, temperature hot spots leading to thermal oxidation of blade coatings, high thermo-mechanical stresses that produce creep damage, fatigue due to blade stress cycling which affects the structural integrity and imposes limits on the engine operating life. Other influence factors are external to the engine, and in some cases beyond the control of the engine or airline operators. These include ambient dust, sand, salt, ice, bird strikes that lead to fouling, erosion, corrosion and foreign object damage respectively, when the engine is exposed to them in the course of its operating profiles. With the accumulation of on-wing time, these degradations not only reduce engine component performance, but also result in higher specific fuel consumption (SFC) and lead to the engine running hotter, with increased turbine entry temperature, and ultimately a reduction in the service life of the hot section components. The rate of degradation is also accelerated for a degraded engine, leading to a faster usage consumption of life-limiting parts.

A key objective of health condition monitoring is, therefore, to assess the performance of an engine at any given time to reveal the presence and if any, the progression of degradation or faults of the components in concern. The results of such diagnostic activity serve as input in predicting the time-to-failure or remaining useful life (RUL) of the affected component and enable adequate logistics and spares to be set in place for maintenance when an overhaul is required. Such health monitoring procedure is also expected to account for the changes in the engine operating profile and how these impact the rate of performance deterioration when making predictions.

Various methods have been developed and proposed for quantifying the effect of adverse operating conditions on the gas turbine health dating as far back as to the Palmgren-Miners rule for calculating cumulative damage and failure resulting from different load cycles [3]. The equivalent time or cycles is also a similar concept that has been applied extensively to land-based gas turbines, especially for power generation applications. General Electric, for example, developed a set of equations to derive maintenance factors that determine the gas turbine combustion and hot gas path inspection intervals based on their operating cycles [4]. The calculated factored hours quantify the impact of different fuel types, load setting or firing temperature and steam/water injection on the hot section component life relative to both baseline operation and inspection interval. According to Lee [5], engine manufacturers also account for the effect of engine start operations on inspection intervals by converting each start cycle to an equivalent number of operating hours. However, these methods cannot be readily applied to aero-gas turbine engines because of the different operating profiles and wide range of conditions encountered in the latter.

For aero-engine life assessment, Zhou et al [6] presented a damage evaluation model for blade creep life calculation, Abdul Ghafir et al [7] used a creep factor parameter to express the relative severity of firing temperatures on life consumption while Eshati et al [8] and Hanumanthan et al [9] adopted the numerical computational approach to solving the same problem. Gotoh et al [10] proposed a method for evaluating gas turbine equivalent operating time for creep and thermo-mechanical fatigue loadings. More recently, Wan et al 
[11] presented an equivalent life index based on a multi-environmental time similarity approach to assess the degradation behaviours of different gas turbine systems operating under different environmental conditions. However, these life-assessment models do not account for the effects of gradual degradation modes that lead to engine performance loss, well before component failure occurs.

OEMs of commercial aircraft engines have also developed bespoke severity curves that define the severity of a given flight operation relative to a reference flight, based on the restoration cost per flight hour and shop visit intervals $[12,13]$. These curves enable the operator to evaluate the effects of thrust rating, take-off and climb derate, FLEX-assumed temperatures, flight length, etc. on engine life-limiting parts and the ensuing direct maintenance and life-cycle costs [14]. For rare events such as flight through volcanic ash clouds, the Duration of Exposure versus Ash Concentration (DEvAC) chart and volcanic ash dosage calculators have been applied to quantify the loss in engine safety margins based on exposure times and ash concentration $[15,16]$. Some of these charts and tools are proprietary, hence the methods for derivation are not publicly available to airline engine operators except that they are applied as factor multiples of the actual flight time or fractions of the time between overhaul. On the other hand, published aero-engine degradation models like in Zaita et al., and Bodjo and Filippone [17,18] which make use of experimental correlations for predicting daily fouling and erosion, lack numerical assessment and verification using engine flight data, mainly due to the unavailability of accurate environmental data acquired during in-flight operations.

This paper addresses these gaps by proposing a novel degradation equivalent operating time (EOT) model, derived from first principles and empirical data correlations, to quantify the severity of engine component degradation from different sources, as a function of internal power settings, ambient and environmental conditions. The output of the model is an equivalent time parameter, which is a factor multiple or fraction of the actual engine flight hours, depending on the severity or mildness respectively of engine operation relative to a reference flight condition. The EOT model was assessed under different operating conditions using steady-state performance simulations of a high-bypass turbofan engine model, thermodynamically similar to the CFM56-7B engine. The application of the EOT model was also demonstrated for single- and multiple-flight scenarios of the engine based on real flight trajectory settings and environmental particulate matter data measured from a dust survey science flight. Finally, the approach was applied to the prognostics of the model engine using implanted component degradation and simulated data, and the results analyzed. The following section describes the formulation of the equivalent operating time model along with the underlying assumptions and methodology for implementation.

\subsection{METHODOLOGY}

\subsection{Fundamental Assumptions}

Engine component degradation is a complex phenomenon, especially when the interaction between simultaneously occurring degradation mechanisms are considered. Hence, the following assumptions have been made with respect to the development of the combined performance deterioration model for the EOT calculation.

1. Only the degradation of major gas path components (i.e. compressors, combustor and turbines) is considered in this study, where each component is considered as a single, brick unit with the air/gas properties defined at the inlet and/or exit stations. 
2. Performance deterioration is assessed based on the health parameters for each component. These include flow capacity and efficiency indices, which represent the changes of the corrected mass flow rate and isentropic efficiency respectively in all operating conditions, relative to their baseline values. A detailed description of the component health parameters is provided by Li and Singh [19].

3. Engine health assessment is performed after every flight using a representative sensor data sample obtained during the steady-state phase of the flight.

4. Environmental parameters such as the size distribution of airborne particulate matter and their respective concentrations are either available or measured during flight.

5. The degradation threshold of each component is assumed to ensure safe operation of gas turbine engines. Such thresholds may be determined by the time between overhauls set by OEM or the maximum allowed component degradations.

6. Finally, the degradation mechanisms considered are limited to fouling and erosion arising from ingested particulate matter and turbine blade tip wear due to its residual inelastic creep strain.

\subsection{Degradation EOT Mathematical Model}

Degradation Equivalent Operating Time (EOT) is the converted operating time for an engine or its components that are operating at a reference condition to attain the same level of degradation when operating at any other condition. This reference condition can be chosen at any operating point, such as the maximum speed at ISA-SLS or cruise flight condition, provided it is convenient for analysis. For a given level of performance degradation $D$, the mathematical formulation for the engine EOT is given as follows:

$$
D=\dot{D}_{\text {ref }} \times E O T=\dot{D} \times t
$$

For a given phase of engine operation in which the conditions are assumed constant, $\dot{D}$ is the rate of degradation at this condition, and $t$ is the time spent at this condition. The degradation rate at the reference condition $\dot{D}_{\text {ref }}$ therefore determines the equivalent operating time which is given in terms of the ratio of degradation rates.

$$
E O T=\frac{\dot{D}}{\dot{D}_{\text {ref }}} \times t
$$

This ratio of actual to reference degradation rates is referred to as the EOT factor as shown in Equation (3). The actual degradation rate can be further expressed in terms of the identified major degradation mechanisms occurring at any given time in addition to the lifelimiting mechanism, such that the overall EOT is given by Equation (4).

$$
\begin{gathered}
\text { EOT }=\text { EOT factor } \times t \\
\text { EOT factor }=\left[1+\frac{\left(\dot{D}_{f}+\dot{D}_{e}+\dot{D}_{x}\right)}{\dot{D}_{\text {ref }}}+\alpha \cdot \frac{\dot{D}_{C}}{\dot{D}_{\text {C.ref }}}\right]
\end{gathered}
$$

where $\dot{D}_{f}, \dot{D}_{e}$ and $\dot{D}_{x}$ are the rates of fouling, erosion and any modelled externally induced degradation mechanism respectively. For the hot section components exposed to high temperature and high-stress environments such as the HP turbine blades, additional parameters are included for the EOT estimation with the life-limiting effect of creep, such 
as the actual total creep consumption rate, $\dot{D}_{C}$, the reference creep rate $\dot{D}_{C . r e f}$ and the contribution of the creep mechanism to diagnosable performance deterioration $\alpha$ via blade tip rubs and the resulting increase in tip clearance. In applying the EOT model to a given engine component, the coefficients of relevant terms must be provided, with those of nonrelated terms set to zero.

For a complete flight mission made up of $n$ micro-phases, the mission EOT is the sum of the individual EOT values evaluated at the different micro-phases, and is given as:

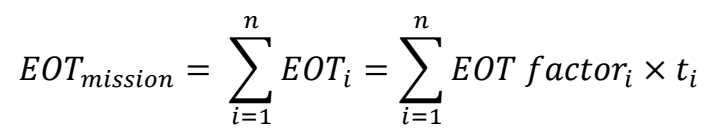

The following sections will be devoted to discussing the formulation of the degradation rate equations for different engine degradation mechanisms.

\subsubsection{Fouling}

Gas turbine fouling refers to the net deposition of small-sized, fine particulate matter or dust suspended in the air, on the surfaces of gas path components. This process alters the aerodynamic blade profile and introduces surface roughness on the blade, hub and end wall surfaces which adversely affects the flow boundary layer [20]. Severe fouling also reduces the cascade flow area, since these particles are known to accumulate in the mid-chord region, down to the trailing edge, especially on the blade suction side [21]. These phenomena are manifested as reductions in the flow capacity and efficiency of the fouled compressors and turbines stages.

In general, the fouling process involves simultaneous deposition of particles on the blade surfaces by adhesion, dislodgement of deposited particles by inertia collision and subsequent particle re-entrainment back into the flow stream. Hence, the net deposition rate can be expressed as the difference between the particle accretion and detachment rates, $\dot{m}_{a c c}$ and $\dot{m}_{\text {det }}$ respectively, as shown in Equations (6) to (8).

$$
\begin{gathered}
\frac{\delta m_{d p}}{\delta t}=\dot{m}_{d p}=\dot{m}_{a c c}-\dot{m}_{d e t} \\
\dot{m}_{a c c}=\dot{m}_{p} P_{c} P_{s} \\
\dot{m}_{d e t}=P_{d} m_{d p}
\end{gathered}
$$

where $\dot{m}_{p}$ is the particle mass flow rate. $P_{c}$ is the particle contact probability, which depends on the engine design features such as the annular flow area, number of blades or blade-pitch per row and inertia of the ingested particles, as expressed by the generalised Stokes number, which is a ratio of the particle characteristic stopping or relaxation time to the flow travel time around the blade surface $[22,23] . P_{S}$ is the particle sticking probability, which depends on target surface conditions such as the presence of a bonding medium e.g. oil, previously formed deposit layer, phase-change temperatures, etc. and condensed water vapour in the air. Combining $P_{c}$ with $P_{s}$ gives the accumulation factor or capture ratio $\zeta$, which is the proportion of ingested particles that will contact and stick to the gas path surfaces. The detachment probability, $P_{d}$ is the ratio of critical to actual particle-wall shear viscosity, $\mu_{c r i t} / \mu_{p}$ [24] or the ratio of actual to critical wall shear fluid velocity, $u_{w a l l} / u_{c r i t}$ [25]. 
The particle flow rate into the engine can be substituted with the product of the particle concentration $\phi_{p}$ and the inlet air mass flow rate $W_{\text {air }}$ i.e. $\dot{m}_{p}=\phi_{p} W_{\text {air }}$, to give:

$$
\dot{m}_{d p}=\zeta \phi_{p} W_{a i r}-\lambda m_{d p}
$$

Integrating the above differential equation by separation of variables, the mass of deposited particles after a given exposure time interval $\Delta t$ can be expressed by the exponentiallyasymptotic relation as in Clarkson and Simpson [15].

$$
m_{d p}(t)=m_{0} e^{-\lambda \Delta t}+\frac{\zeta \phi_{p} W_{a i r}}{\lambda}\left(1-e^{-\lambda \Delta t}\right)
$$

where $m_{0}$ is the initial mass of particles deposited from previous exposure. For an initial clean, unfouled component, $m_{0}=0$ and Equation (10) becomes:

$$
m_{d p}(t)=\frac{\zeta \phi_{p} W_{\text {air }}}{\lambda}\left(1-e^{-\lambda \Delta t}\right)
$$

where the exponential term can be expanded as a Taylor series:

$$
e^{-\lambda \Delta t}=1-\lambda \Delta t+\frac{(\lambda \Delta t)^{2}}{2 !}-\frac{(\lambda \Delta t)^{3}}{3 !}+\cdots
$$

Neglecting higher-order terms, the initial mass of deposited particles can be expressed as a linear function of the exposure time interval $\Delta t$ as shown in Equation (13).

$$
m_{d p}(t)=\zeta \phi_{p} W_{\text {air }} \cdot \Delta t
$$

where the unit time interval of analysis, $\Delta t=1 \mathrm{sec}$. is infinitesimal, compared to the total flight operating time of the engine and its components. This calculated initial mass of deposited particles can then be substituted for $m_{0}$ in Equation (10) to obtain the progressive deposition rates and quantities at subsequent exposure time steps.

To account for ambient temperature and pressure deviations from standard or reference atmospheric conditions, the corrected mass flow rate $W_{\text {corr }}$ is substituted for $W_{\text {air }}$, according to Equation (14).

$$
W_{\text {corr }}=W_{\text {air }} \times \frac{\sqrt{T_{a} / T_{\text {ref }}}}{P_{a} / P_{\text {ref }}}
$$

Since neither of the above flow parameters is known in flight, $W_{\text {corr }}$ must be expressed as a function of a measured, engine control handle, such as the corrected fan speed, $N_{1 r}$. For the case study engine, the relation between $W_{\text {corr }}$ and $N_{1 r}$ was determined by the parametric fitting of a quadratic function to the part-speed simulation results of the engine model. The general form of Equation (13) in terms of the engine handle is given as:

$$
m_{d p}(t)=\zeta \phi_{p} \cdot \frac{P_{a}}{P_{\text {ref }}} \sqrt{\frac{T_{r e f}}{T_{a}}} \cdot f\left(N_{1 r}\right) \cdot \Delta t
$$

where 


$$
W_{\text {corr }}=f\left(N_{1 r}\right)=74.388 \cdot N_{1 r}^{2}-31.119 \cdot N_{1 r}+24.086
$$

For a maximum capture ratio $\zeta_{\max }$ in dry, unsaturated air of 0.5 , the additional effect of ambient relative humidity, $R H_{0}$ takes the form of a logistic function in Equation (17) as determined from the simulation of the engine model. The growth rate, $k=2.736$ was chosen such that $\zeta_{\max }=0.99$ when $R H_{0}=100 \%$ at the reference corrected fan speed.

$$
\zeta_{\max }=\left\{\begin{array}{cc}
0.5 & \text { for } 0 \leq R H_{0} \leq 28.35 \% \\
\frac{1}{\left[1-e^{-k\left(R H_{0}-28.35\right)}\right]} & \text { for } 28.35 \% \leq R H_{0} \leq 100 \%
\end{array}\right.
$$

Finally, the initial loss in component health parameters due to fouling, $\Delta X_{f}$ can be given as:

$$
\Delta X_{f} \equiv D_{f}=k_{f} k_{d} \cdot \zeta \phi_{p} \cdot \frac{P_{a}}{P_{r e f}} \sqrt{\frac{T_{r e f}}{T_{a}}} \cdot f\left(N_{1 r}\right) \cdot \Delta t
$$

where $k_{f}$ is the fouling factor that expresses the loss in either component flow capacity or efficiency health index due to a unit mass of deposited particles, and $k_{d}$ is the distribution factor, since an uneven deposit film is expected for the 3-D flow in each component blade row.

Although gas turbine fouling is strongly non-linear against actual clock time and with respect to changing ambient, environmental and operating conditions, the fouling EOT which expresses the actual fouling rate relative to the nominal rate at a reference condition, can account for the non-linearity of these external factors. Hence, fouling degradation can approach a linear relation against the influence factors when expressed as a function of the EOT for each time interval.

\subsubsection{Erosion}

Erosion in gas turbines involves the abrasive removal of material from the gas path component surfaces due to the impact of high-velocity, hard particles of significant size, contained in the ingested air. Erosion damage is commonly associated with bluntness of the leading edge, and thinning of tip regions and trailing edge of compressor blades, which modifies the aerofoil profile, increases surface roughness and blade running clearance $[26,27]$. This produces a loss in the flow capacity and efficiency of the affected blade rows or stages. In the turbine, however, acceleration of the particles through the nozzle guide vanes (NGV) produces more erosion at the throat and towards the trailing edge, leading to an increase in the turbine flow capacity as the efficiency drops [28]. According to Diakunchak [29], erosion is usually caused by sand particles, $20 \mu \mathrm{m}$ or more in diameter, when present in sufficient quantities. Meher Homji et al. [30] and Jacobson [31], however, posited that particles above $10 \mu \mathrm{m}$ in diameter would cause erosion in gas turbines.

For an ingested flow of particles with similar physical composition above the erosion size threshold and a known particle size distribution, the component material removal (erosion) rate $E_{r}$ can be expressed in Equation (19) [32].

$$
E_{r} \propto \sum_{i=1}^{N} \dot{m}_{p_{i}} d_{p_{i}} v_{p_{i}}^{\alpha}
$$


where $N$ refers to the number of particle measurement channels above $10 \mu \mathrm{m}$ and the subscript $i$ denotes each channel of mean size $d_{p_{i}}, \dot{m}_{p_{i}}$ is the mass flow rate of ingested particles in band $i$, and $v_{p_{i}}$ is the impacting velocity of the particles, $\alpha$ is the velocity exponent, which has been determined from erosion tests to be between 2.0 and 2.3 for relatively small particles [33]. For this study, $\alpha=2$ is used.

Substituting the individual impact velocities $v_{p_{i}}$ with a mean value $\bar{v}_{p}$, and expressing $\dot{m}_{p_{i}}$ in terms of particle concentration in air, $\dot{m}_{p}=\phi_{p_{i}} W_{\text {air }}$, the erosion rate becomes:

$$
E_{r}=k_{r} W_{\text {air }} \bar{v}_{p}^{2} \sum_{i=1}^{N} \phi_{p_{i}} d_{p_{i}}
$$

where $k_{r}$ is the dimensionless erosion rate which comprises material-dependent factors, such as particle hardness and shape, blade material and coating properties, etc. that influence material removal but does not necessarily vary with engine operating conditions.

The summation term above can be aggregated into an effective particle size parameter $D_{p}$, where the contribution of each bin size $d_{p_{i}}$ to the total erosion rate is weighted by its relative concentration in the air $\phi_{p_{i}} / \sum \phi_{p}$. If $\Phi_{p_{N}}$ is the sum of measured particle concentrations $\sum \phi_{p}$, then Equation (20) becomes:

$$
E_{r}=k_{r} W_{a i r} \bar{v}_{p}^{2} D_{p} \Phi_{p_{N}}
$$

where:

$$
D_{p}=\frac{\sum_{i=1}^{N} \phi_{p_{i}} d_{p_{i}}}{\sum_{i=1}^{N} \phi_{p_{i}}} \equiv \frac{\sum_{i=1}^{N} \phi_{p_{i}} d_{p_{i}}}{\Phi_{p_{N}}}
$$

The mean particle velocity can also be expressed in terms of the air axial velocity within the engine, based on the force equilibrium assumption for a body in a Newtonian fluid [34].

$$
\bar{v}_{p}=v_{z}\left(1-e^{-t_{\tau} / \tau}\right)
$$

where $v_{z}$ is the fluid (air or gas) axial velocity, $\tau$ is the response time constant representing the time required for the particles, initially at the same velocity as the fluid, to decay to approximately $1 / e$ of their initial value and $t_{\tau}$ is the elapsed travel time, which is measured from the exit of an engine component that impacts energy to the air or gas, such as the fan or compressor. The erosion rate becomes:

$$
E_{r}=k_{r} W_{\text {air }} D_{p} v_{z}^{2}\left(1-e^{-t_{\tau} / \tau}\right)^{2} \Phi_{p_{N}}
$$

Since $W_{\text {air }}$ is also a function of the air density $\rho_{a}$, flow area $A_{a n n}$ and axial velocity $v_{z}$ according to $W_{\text {air }}=\rho_{a} A_{a n n} v_{z}$, then substituting for $v_{z}$ as in Equation (25) yields:

$$
E_{r}=\frac{k_{r} W_{\text {air }}^{3} D_{p} \Phi_{p_{N}}}{\rho_{a}^{2} A_{\text {ann }}^{2}}\left(1-e^{-t_{\tau} / \tau}\right)^{2}
$$

Correcting the effects of ambient conditions and substituting the engine handle, $N_{1 r}$ as in Equation (14), the erosion rate can be expressed as: 


$$
E_{r}=\frac{k_{r} D_{p} \Phi_{p_{N}}}{\rho_{a}^{2} A_{\text {ann }}^{2}}\left[\frac{P_{a}}{P_{\text {ref }}} \sqrt{\frac{T_{r e f}}{T_{a}}} \cdot f\left(N_{1 r}\right)\right]^{3}\left(1-e^{-t_{\tau} / \tau}\right)^{2}
$$

In terms of the impact on the component health parameters, the degradation due to erosion $\Delta X_{e}$ can be expressed as in Equations (27) and (28):

$$
\begin{gathered}
\Delta X_{e}=E_{r} \cdot \Delta t \\
\Delta X_{e} \equiv D_{e}=\frac{k_{e} k_{r} D_{p} \Phi_{p_{N}}}{\rho_{a}^{2} A_{a n n}^{2}}\left[\frac{P_{a}}{P_{r e f}} \sqrt{\frac{T_{r e f}}{T_{a}}} \cdot f\left(N_{1 r}\right)\right]^{3}\left(1-e^{-t_{\tau} / \tau}\right)^{2} \cdot \Delta t
\end{gathered}
$$

where $k_{e}$ is the erosion factor relating the component flow capacity or efficiency loss due to a unit mass of material removed from the rotor or stator blades and the resulting surface roughness.

\subsubsection{Creep-Strain Mechanism}

In addition to the above degradation processes, the hot section gas path components such as turbine rotor disk, blades and vanes are exposed to additional failure mechanisms that limit their achievable service life. Some of these failure modes also modify the turbine flow geometry, leading to detectable deterioration in engine performance. For example, the inelastic elongation due to creep of HP turbine blades over engine life can cause the blade tips to rub on the casing seal more frequently during transient acceleration from idle to maximum speed at take-off or early climb [35]. This results in increased blade tip-seal clearance during the cruise phase and reduced turbine efficiency as more hot gases are lost as over-tip flows from the pressure side to the suction side. The performance impact is a continuous increase in the engine's SFC over time since the blades are not restored to their initial length. For this study, only the effect of HP turbine blade creep strain on HP turbine health parameters was analysed for inclusion in the EOT equation.

Previous studies investigating the effect of operating conditions of gas turbine creep damage have considered them as separate from component degradation mechanisms $[7,8,36]$. However, this failure mechanism which is initiated at the micro-structural level, has a significant impact on the physical geometry and tip surface quality of the blades, which affects the critical gas path flow area and stage efficiency.

The creep model used is based on the Larson-Miller Parameter (LMP) $P$ that relates the time to creep failure $t_{f}$ of a material to the subjected stress $\sigma$ and temperature $T$ shown in Equation (29) [7].

$$
P(\sigma)=\frac{T}{1000}\left(\log t_{f}+C\right)
$$

where $\mathrm{C}$ is a material constant which is set to 20 for most metal alloys.

The LMP can also be applied to determine the time to a certain creep strain value, before actual creep failure, as a function of stress and temperature. Thus, the time taken for a turbine blade to reach $1 \%$ creep strain, $t_{\varepsilon_{c}=1 \%}$ can be expressed as a function of the blade temperature $T_{b}$ and the stress function for $1 \%$ creep strain, $P(\sigma)_{1 \%}$ as: 


$$
t_{\varepsilon_{C}=1 \%}=10 \frac{1000 \cdot P(\sigma)_{1 \%}}{T_{b}}-C
$$

and the creep strain rate can be expressed as:

$$
\varepsilon_{c}=\frac{1}{t_{\varepsilon_{C}=1 \%}}=10^{-\left(\frac{1000 \cdot P(\sigma)_{1 \%}}{T_{b}}-C\right)}
$$

If the turbine blade tips are just clear of the casing seal at the maximum take-off speed (as obtainable after wear-in of a new engine), then any plastic growth in the blade will cause tip rubs and wear of the casing seal or blade, leading to increased tip gaps. The effect of increased tip clearance $\delta$ on the turbine efficiency $\eta_{T}$ as proposed by Baskherone [37] is given in Equation (32).

$$
\frac{\eta_{T}}{\eta_{T_{-} r e f}}=1-K\left(\frac{\delta}{L_{b}}\right)\left(\frac{r_{\text {tip }}}{r_{\text {mean }}}\right)
$$

where $\eta_{T_{-} \text {ref }}$ is the reference turbine efficiency, $L_{b}$ is the blade span, $r_{\text {tip }}$ and $r_{\text {mean }}$ are the radii from the engine axis to the blade tip and mean-line respectively. $K$ is a blade-design constant given by:

$$
K=1+0.586\left(\psi_{Z_{t i p}}{ }^{3.63}\right)
$$

where $\psi_{z_{\text {tip }}}$ is the Zwiffel coefficient, which is the pitch-to-axial-chord ratio, $S / c_{z}$ at the blade tip, and given in terms of the blade inlet and outlet angles $\beta_{1}$ and $\beta_{2}$ in Equation (34).

$$
\psi_{z_{t i p}}=\frac{2 S_{t i p}}{c_{z, t i p}} \cos ^{2} \beta_{2}\left[\tan \beta_{1}-\tan \beta_{2}\right]
$$

The flow capacity and efficiency degradation levels due to the creep-strain-induced blade tip-seal wear can be presented as:

$$
\begin{gathered}
\Delta X_{c_{-} f c}=1-\frac{\delta}{\delta_{r e f}} \\
\Delta X_{c_{-} e f f}=1-\frac{\eta_{T}}{\eta_{T_{-} r e f}}
\end{gathered}
$$

\subsection{EOT Model Implementation}

The process flow diagram in Figure 1 describes the methodology for computing the postflight equivalent operating time of an aircraft gas turbine using in-flight sensor recordings and physical degradation models for the affected component health indices. The fundamental requirement is an engine model which defines each gas path component state via the thermodynamic properties of the air/gas flowing through them. This engine model must be representative of the actual engine steady-state behaviour in terms of the configuration, component characteristic maps, control schedule, bleed systems, auxiliary power off-takes, mechanical losses and performance output.

After each flight mission, a steady-state sample of the flight data is selected and then preprocessed for noise reduction and data correction to a reference condition. The sensor 
deviation or fault signature is provided as input for diagnostics of the gas path components to predict the inherent degradation. This can be accomplished using gas path diagnostic techniques, such as the non-linear, multiple-component GPA technique described by Li et al [38]. The predicted degradation in flow capacity and efficiency for each component is then re-implanted to update the engine model and its performance is simulated for all flight conditions. Thus, both measured parameters and other important engine parameters for which no sensors are installed, are generated. Examples of the latter include the temperature, pressure, density and mass flow rate at the HP turbine NGV and rotor inlet stations.

Simultaneously, atmospheric particle size distribution and concentration in the vicinity of the engine inlet may be gathered by direct measurement using aircraft-fitted aerosol particle counters, at the same sampling rate. Both environmental and relevant engine parameters are fed into the component-aerosol interaction model, which calculates the impact of the ingested particles on the component performance deterioration as presented in Figure 2. In the HP turbine where blade tip-rubs on the casing during rapid acceleration and high pitch or yaw angle manoeuvers may be an additional source of degradation, the simulated turbine inlet measurements become an input to a blade creep strain and tip clearance sub-models. These evaluate the blade tip clearance based on calculated thermo-mechanical strains in the turbine blades and shroud-casing for each measured operating condition. In the event of contact between the blade and the casing seal due to blade plastic elongation, the impact of material loss on the performance of the turbine may also be computed.

With the above information, the EOT factor is obtained by expressing the component degradation rate relative to its reference value. The Equivalent Operating Time is then calculated by multiplying the actual flight time by the EOT factor and compared to the operating limit set by the engine manufacturer. If the total consumed EOT is less than this limiting operation threshold, the Remaining Useful Life (RUL) is calculated. Otherwise, the component must undergo a physical inspection to determine if its true condition deserves engine removal or overhaul. It is noteworthy that where the EOT exceeds the threshold, the engine may be yet to attain this limit in actual flight hours. However, the use of EOT based on the severity of the historical engine operating profile enables the operator to monitor the true engine experience in addition to the on-wing time, and make well-informed, conditionbased, maintenance scheduling decisions. 


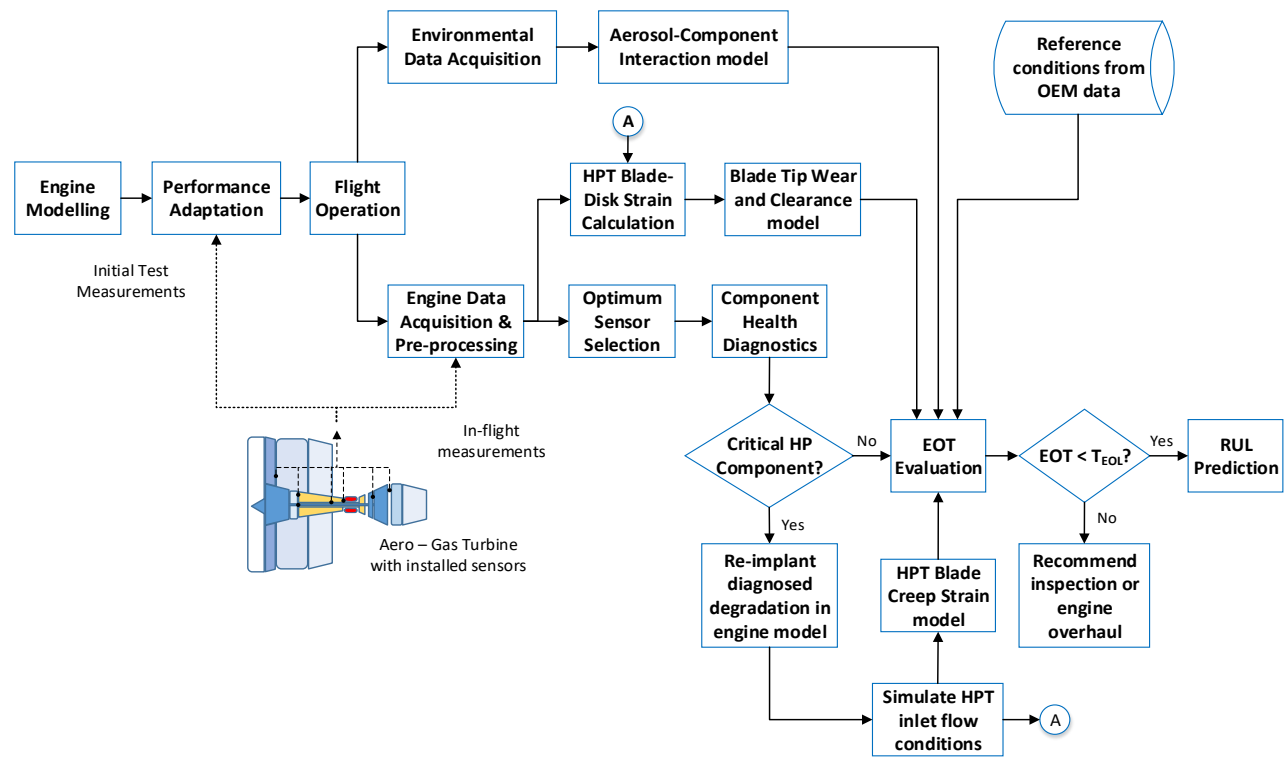

Figure 1 Implementation of the EOT assessment model. 


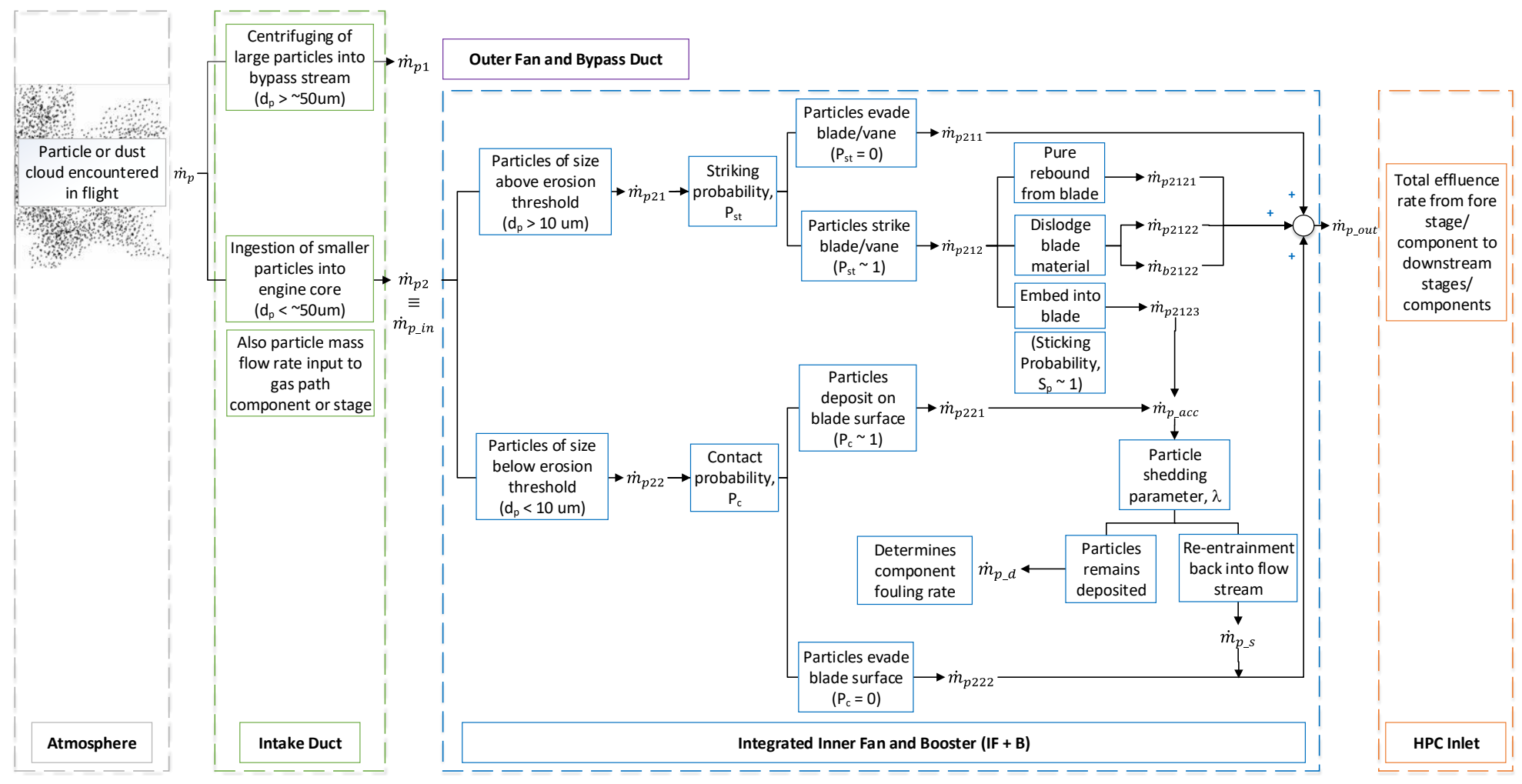

Figure 2 Mass flow balance of ingested particles through the integrated inner fan and booster compressor. 


\subsection{ENGINE PERFORMANCE MODEL VALIDATION}

For this study, an aero gas turbine performance model similar to CFM56-7B engine, which is a 2-spool turbofan powering the Boeing $737 \mathrm{NG}$ fleet for a mid-long haul transport, was chosen. The engine model was set up and its performance adapted and simulated using the Cranfield University's gas turbine simulation and diagnostics software, PYTHIA [19]. Figure 3 shows the schematic of the engine model with air bleed network and station numbers. The nominal performance of the engine at take-off for sea-level static ISA conditions is given as follows [39]:

- Takeoff thrust

- Total pressure ratio

- Maximum fan speed

- Bypass ratio

- SFC

- Exhaust gas temperature $\left(\mathrm{T}_{5}\right)$

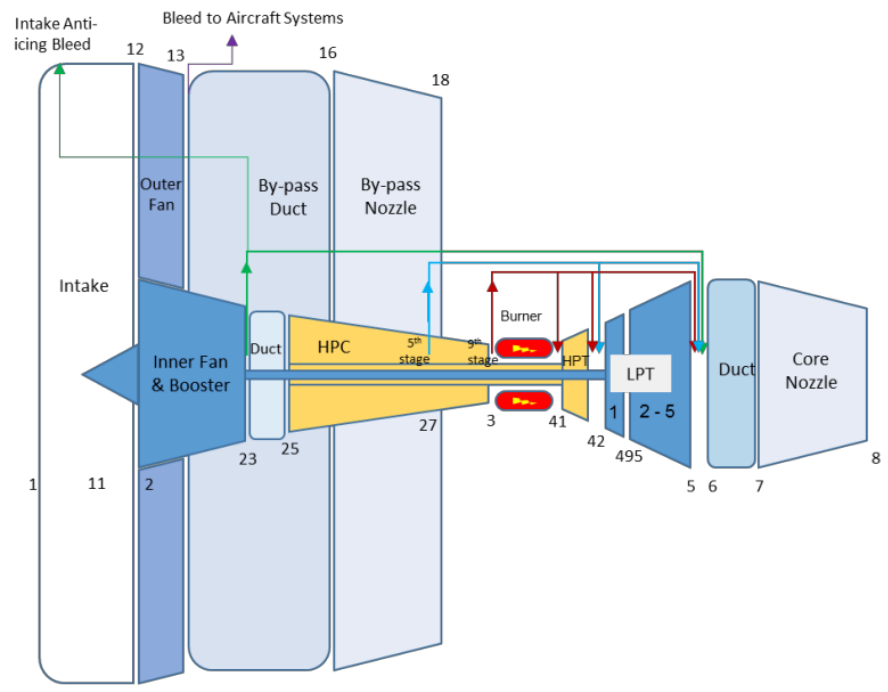

Figure 3 Turbofan Engine Model.

\subsection{Performance Adaptation}

To match the engine model performance to the real engine sensor readings obtained from part-load operation at the start of its ground test, both design point and off-design performance adaptation were performed. The design point adaptation was done using the non-linear Adaptation Coefficient Matrix method [40] to tune the component parameters in order to match the test measurements at the chosen design point of $91.62 \%$ maximum fan speed. The accuracy of the model after design point adaptation is presented in Table 1, with all measurement errors below $0.001 \%$. Due to the confidential nature of the engine data, only the initial and final errors are shown. 
The off-design adaptation was done using a Genetic Algorithm [41] to optimize and scale the flow capacity, efficiency and pressure ratios in the OEM compressor and turbine maps, and efficiency in the combustor map, in order to match the measurements at lower speed lines. Three (3) off-design data sets at conditions shown in Table 2 were found to produce the minimum overall error between simulated and target measurements, compared to other cases investigated. The root mean squared (RMS) error between the predicted and target measurements was the objective function minimized by the GA.

Table 1 Design Point Adaptation Errors for Engine Performance Parameters

$\begin{array}{cccc}\text { Target Performance Parameter } & \begin{array}{c}\text { Symbol } \\ \text { Initial } \\ \text { Error (\%) }\end{array} & \begin{array}{c}\text { Post-Adaptation } \\ \text { Error (\%) } \\ 4.7 \mathrm{e}-5\end{array} \\ \text { Engine inlet total pressure } & \mathrm{P}_{10} & 1.38 & 2.5 \mathrm{e}-5 \\ \text { HPC inlet total temperature } & \mathrm{T}_{25} & 3.53 & 3.8 \mathrm{e}-5 \\ \text { HPC inlet total pressure } & \mathrm{P}_{25} & -2.96 & 6.1 \mathrm{e}-5 \\ \text { HPC exit total temperature } & \mathrm{T}_{3} & 5.58 & 2.2 \mathrm{e}-6 \\ \text { HPC exit total pressure } & \mathrm{P}_{3} & 12.32 & 5.7 \mathrm{e}-5 \\ \text { LPT NGV 1 exit total temperature } & \mathrm{T}_{495} & 5.00 & 2.3 \mathrm{e}-4 \\ \text { LPT NGV 1 exit total pressure } & \mathrm{P}_{495} & 5.99 & 1.4 \mathrm{e}-4 \\ \text { LPT exit total temperature } & \mathrm{T}_{5} & 4.66 & 5.8 \mathrm{e}-4 \\ \text { LPT exit total pressure } & \mathrm{P}_{5} & 6.74 & 1.4 \mathrm{e}-4 \\ \text { Fuel flow } & \mathrm{W}_{\mathrm{FF}} & 6.26 & 2.0 \mathrm{e}-4 \\ \text { Net thrust } & \mathrm{F}_{\mathrm{N}} & 1.83 & --\end{array}$

The plots in Figure 4 show the outcome of the component map tuning on some key measurement turbine parameters. For the other parameters, the initial errors before adaptation were not significant. The improved accuracy of the model to within $98 \%$ of the engine data at lower speed setting highlights the importance of the off-design adaptation procedure.

Table 2 Design Point and Off-design Adapted Condition Settings

$\begin{array}{cccc}\text { Data } & \begin{array}{c}\text { Ambient } \\ \text { Temperature } \\ \left({ }^{\mathbf{0}} \mathbf{C}\right)\end{array} & \begin{array}{c}\text { Ambient } \\ \text { Pressure } \\ (\mathbf{a t m})\end{array} & \begin{array}{c}\text { Corrected } \\ \text { Fan Speed } \\ \mathbf{( \% )}\end{array} \\ \text { Adapted design point } & 7.0 & 0.9873 & 91.62 \\ \text { Off-design setting 1 } & 7.0 & 0.9874 & 87.09 \\ \text { Off-design setting 2 } & 6.9 & 0.9877 & 85.08 \\ \text { Off-design setting 3 } & 6.6 & 0.9875 & 80.19\end{array}$


(a) LPT NGV 1 Exit Total Temperature

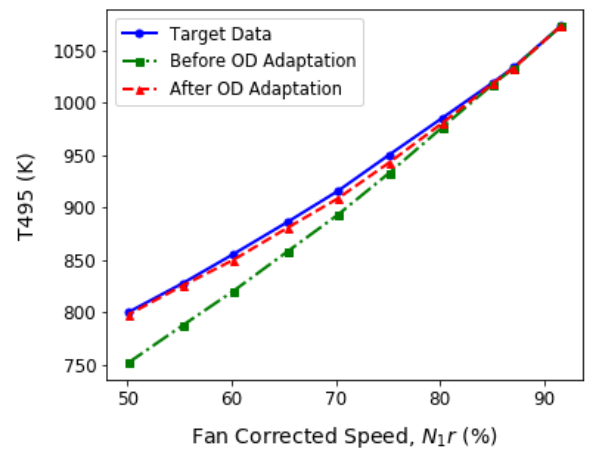

(b) LPT Exit Total Temperature

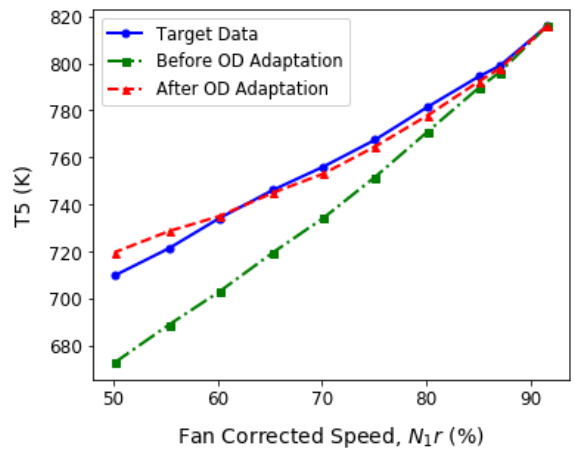

Figure 4 Comparison between the target and simulated engine model measurements before and after off-design adaptation.

\subsection{Optimum Sensor Selection for Diagnostics}

Although engine measurements from 14 installed gas path sensors were available, sensors that provide the most visibility of engine faults had to be identified using the selection procedure proposed by Jasmani et al. [42]. The fault sensitivity of the sensors was obtained by implanting $1 \%$ degradation in each component health index and simulating the engine model measurement parameters at constant corrected fan speed and in off-design mode. The resulting measurement sensitivity is revealed in Figure 5 and summarized using the sensitivity norm in Table 3, where it can be seen that the fuel flow ( $\mathrm{W}_{\mathrm{FF}}$ ) is the most sensitive to component faults and the fan exit total temperature $\left(\mathrm{T}_{13}\right)$ is the least sensitive.

(a)

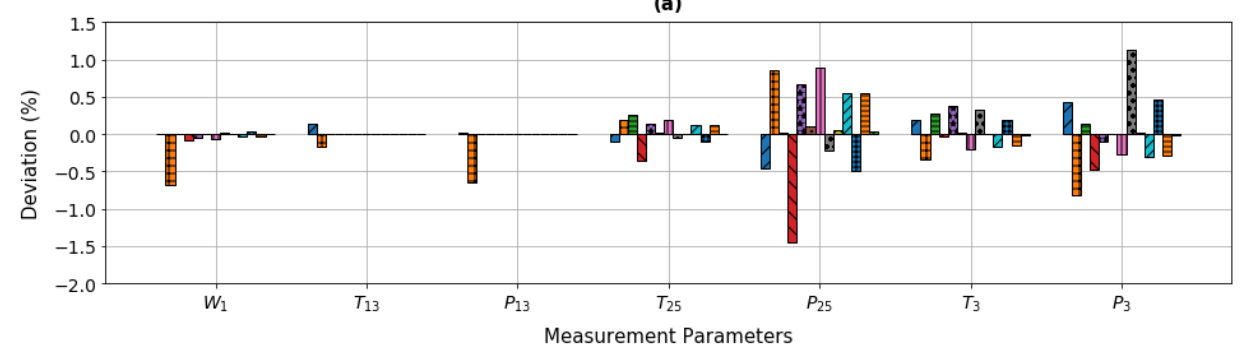

(b)

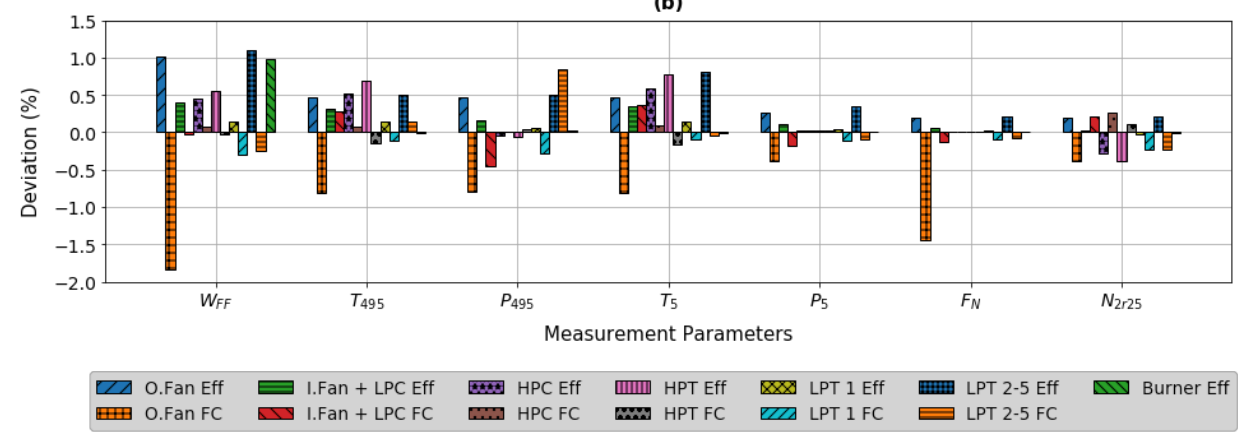

Figure 5 Simulated sensor deviations for unit degradation in component health parameters. 
Table 3 Normalized sensor sensitivity

$\begin{array}{cccccccc}\text { Parameters } & \mathbf{W}_{\mathbf{1}} & \mathbf{T}_{13} & \mathbf{P}_{13} & \mathbf{T}_{\mathbf{2 5}} & \mathbf{P}_{\mathbf{2 5}} & \mathbf{T}_{\mathbf{3}} & \mathbf{P}_{\mathbf{3}} \\ \text { Sensitivity Norm } & 0.688 & 0.221 & 0.642 & 0.582 & 2.289 & 0.773 & 1.697 \\ & & & & & & & \\ \text { Parameters } & \mathbf{W}_{\mathbf{F F}} & \mathbf{T}_{495} & \mathbf{P}_{495} & \mathbf{T}_{\mathbf{5}} & \mathbf{P}_{\mathbf{5}} & \mathbf{F}_{\mathbf{N}} & \mathbf{N}_{\mathbf{2} 25} \\ \text { Sensitivity Norm } & 2.719 & 1.461 & 1.472 & 1.681 & 0.640 & 1.485 & 0.828\end{array}$

Analysis of the correlation between sensors to identify those with similar fault signature profiles for deselection was also done. $\mathrm{P}_{13}$ was found to be highly correlated with Mass flow $\left(\mathrm{W}_{1}\right)$ and Net thrust $\left(\mathrm{F}_{\mathrm{N}}\right)$ so that the 2 least sensitive sensors out of these 3 were eliminated. Although $\mathrm{T}_{495}$ is seen to be highly correlated and less sensitive when compared with $\mathrm{T}_{5}$, it was retained since it gives the best indication of the crucial TET, especially for the HP turbine component subset.

An optimum subset of 8 sensors was finally selected, comprising 7 main sensors for the gas path components and 1 for redundancy in the event of a sensor fault as shown in Table 4. This subset is capable of producing the most relevant and unique fault signature needed to accurately isolate and predict faults in all possible component fault cases using the Gas Path Analysis (GPA) diagnostics method [38].

Table 4 Selected optimum sensors for diagnostics

$\begin{array}{cc}\mathbf{S} / \mathbf{N} & \text { Sensor } \\ 1 & \mathrm{P}_{25} \\ 2 & \mathrm{P}_{3} \\ 3 & \mathrm{~T}_{495} \\ 4 & \mathrm{P}_{495} \\ 5 & \mathrm{~T}_{5} \\ 6 & \mathrm{~W}_{\mathrm{FF}} \\ 7 & \mathrm{~N}_{2 \mathrm{r} 25} \\ 8 & \mathrm{~F}_{\mathrm{N}}\end{array}$

Description
Booster exit total pressure (atm)
HP compressor inlet total pressure (atm)
LP turbine stage 2 inlet total temperature $(\mathrm{K})$
LP turbine stage 2 inlet total pressure $(\mathrm{atm})$
LP turbine exit total temperature $(\mathrm{K})$
Fuel flow $(\mathrm{kg} / \mathrm{s})$
HP spool relative corrected speed $(\%)$
Net thrust $(\mathrm{kN})$

Component Subset

Inner fan + Booster

HPC

HPT

LPT 1

LPT 2-5

Burner

$\mathrm{HPT} / \mathrm{HPC}$

Outer fan

\subsection{EFFECT OF OPERATING CONDITIONS ON EOT}

To assess the effect of changes in engine operating conditions on the EOT factors for fouling, erosion and creep-strain wear degradation, under constant particle size distribution and concentration, the adapted engine model performance was simulated for various cases. These include changes in altitude, Mach number, ambient temperature and relative humidity, all under constant fan speed, as well as a separate part-speed simulation.

\subsection{Changes in Altitude}

Figure 6 shows the deviations in key engine parameters with respect to their reference values, for step changes in take-off altitude from $500 \mathrm{~m}$ below sea-level to $5000 \mathrm{~m}$ above. With increasing altitude, the ambient temperature drops linearly, with the air density and pressure dropping exponentially. The constant fan speed control schedule leads to an increase in the corrected fan speed, and therefore a rise in the pressure ratio and corrected air mass flow through the engine, as inferred from the inner fan and booster map. However, 
the actual core air mass flow decreases, leading to a drop in the ingestion rate for a given unit particle concentration in air.

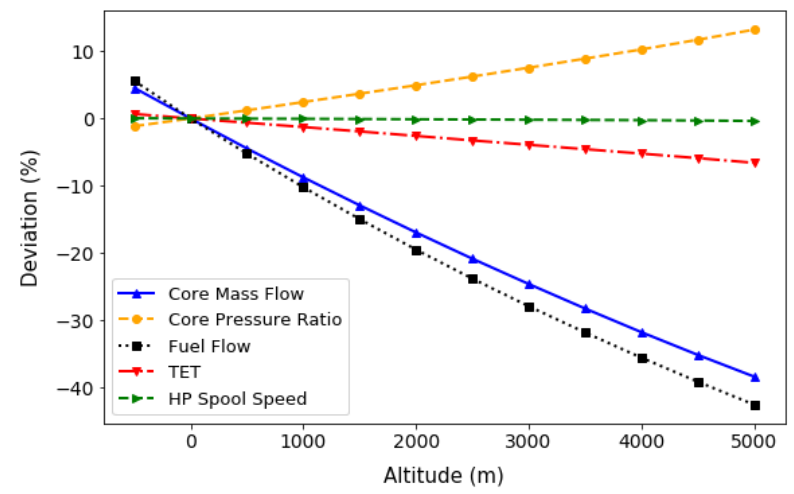

Figure 6 Deviations in performance parameters with changes in altitude.

In Figure 7, the EOT fouling factor in the inner fan + booster component relative to the reference sea-level condition starts at 1.05 and drops at an average rate of $0.4 \%$ for every $100 \mathrm{~m}$. The relative erosion factor, which depends on the air/particle velocity in addition to the mass flow rate, drops initially at a gradient of 0.0143 per $100 \mathrm{~m}$, down to 0.004 per 100 $\mathrm{m}$. In the HP turbine, relative fouling and erosion EOT factors follow similar trends to those in Figure 7(a) due to the turbine mass flow rate being the sum of the engine air inlet flow and the fuel flow rates minus the compressor bleeds. However, they are less sensitive to altitude variation compared to the thermo-mechanical creep effects. Hence, the relative creep-strain EOT factor reduces with TET from an initial rate of 0.035 per $100 \mathrm{~m}$ and asymptotes to 0.001 at $5000 \mathrm{~m}$.

(a) Integrated Inner Fan + Booster

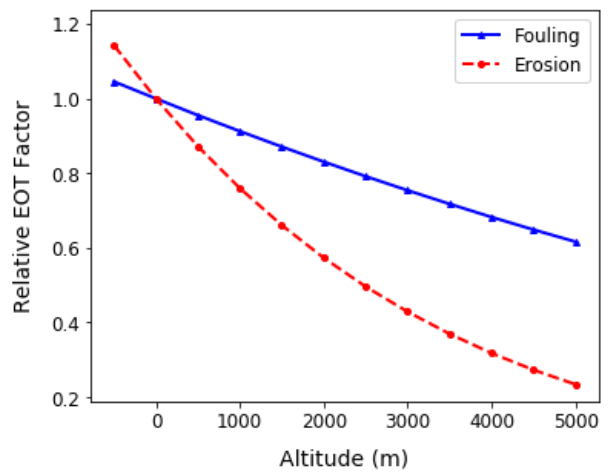

(b) HP Turbine

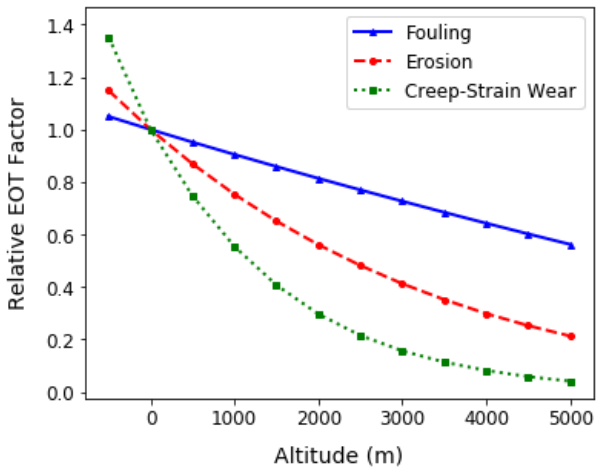

Figure 7 EOT factors for (a) inner fan + booster, and (b) HP turbine degradations, relative to the reference condition for changing altitude.

\subsection{Changes in Flight Mach Number}

The engine performance summary obtained from the simulation of increasing Mach number from 0 to 0.5 at constant sea-level altitude and fan speed is presented in Figure 8. The observed trends can be ascribed to the ram compression in the intake duct, which causes the 
stagnation temperature, pressure and air mass flow rate at the fan inlet to increase. At constant fan speed, the booster pressure ratio and corrected mass flow drop as dictated by the characteristic map. However, due to the ram pressure ratio being greater than the ensuing temperature ratio, the actual intake mass flow increases.

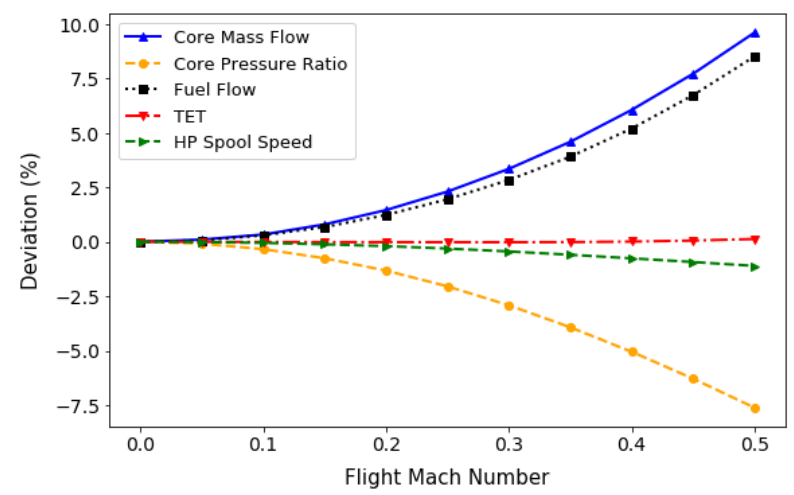

Figure 8 Deviations in performance parameters with changes in flight Mach number.

The increased mass flow causes the relative fouling effect to increase non-linearly at a constant rate up to a factor of 1.10 at the maximum permissible sea-level $\mathrm{Ma}=0.5$ as shown in Figure 9(a) and (b). The relative erosion factor, however, follows an exponential trend, with an initial growth rate of 0.058 at $\mathrm{Ma}=0.05$ up to 1.34 at $\mathrm{Ma}=0.5$ and an EOT factor of 1.32 at $\mathrm{Ma}=0.5$. For the HP turbine, the final creep-strain EOT factor at $\mathrm{Ma}=0.5$ is 1.26 due to the increased TET needed to accelerate the engine/aircraft.
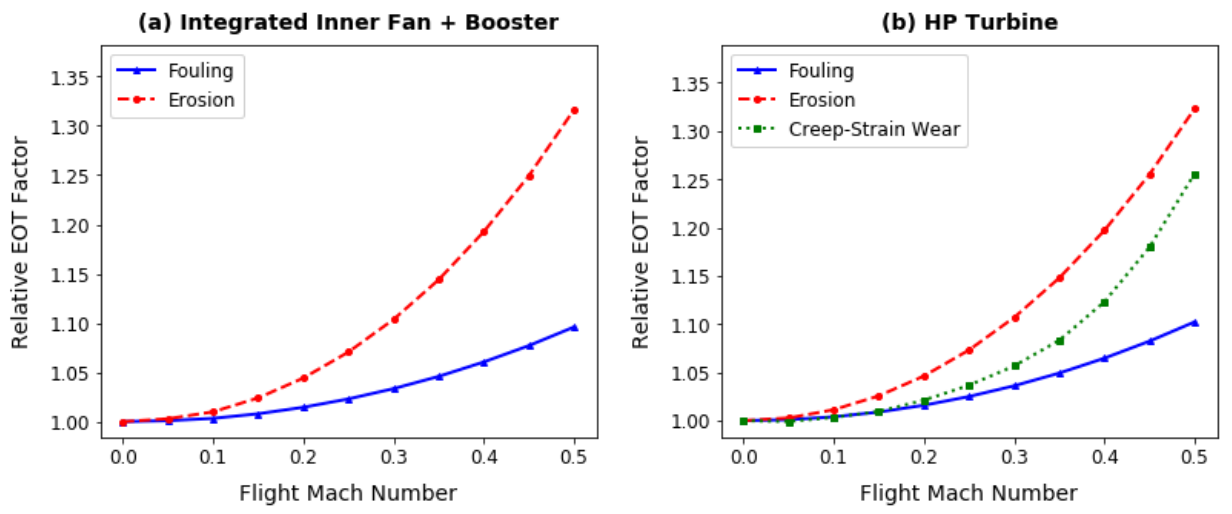

Figure 9 EOT factors for (a) inner fan + booster, and (b) HP turbine degradations, relative to the reference condition for changing flight Mach number.

\subsection{Changes in Ambient Temperature}

The effects of changes in ambient temperature at sea-level on key performance parameters are plotted in Figure 10. On a relatively hot day, the air entering the engine is less dense than normal, leading to a reduction in the corrected mass flow rate and booster pressure ratio as the corrected fan speed reduces. The actual mass flow rate, therefore, drops by a larger extent than its corrected equivalent, given that the inlet pressure remains unchanged. 
This leads to a reduction in the calculated EOT fouling and erosion factors relative to the reference condition when the engine operates under constant ambient particle concentration. This phenomenon is reversed on a colder day, as the fouling and erosion factors increase.

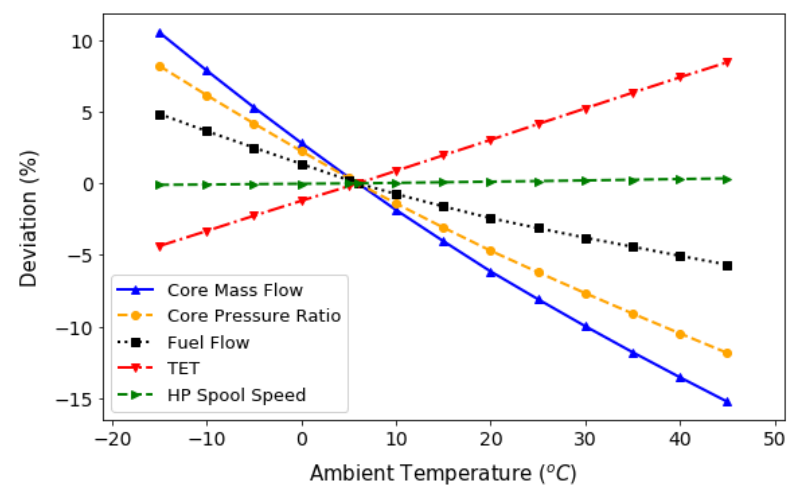

Figure 10 Deviation in performance parameters with changes in ambient temperature.

Figure 11(a) and (b) shows that for a reference temperature of $7{ }^{\circ} \mathrm{C}$, the relative fouling factor drops by an average factor of 0.027 for every $5{ }^{\circ} \mathrm{C}$ rise in ambient temperature. The erosion rate follows a more non-linear demise, starting steeply with a relative EOT factor of 1.35 and -0.095 gradient at $-15^{\circ} \mathrm{C}$ and ending with 0.6 erosion factor and -0.037 gradient at $45{ }^{\circ} \mathrm{C}$. The HP turbine creep-strain EOT factor increases exponentially with day temperature up to 35 times at $45^{\circ} \mathrm{C}$, which enhances the importance of take-off and climb de-rate on hot days.
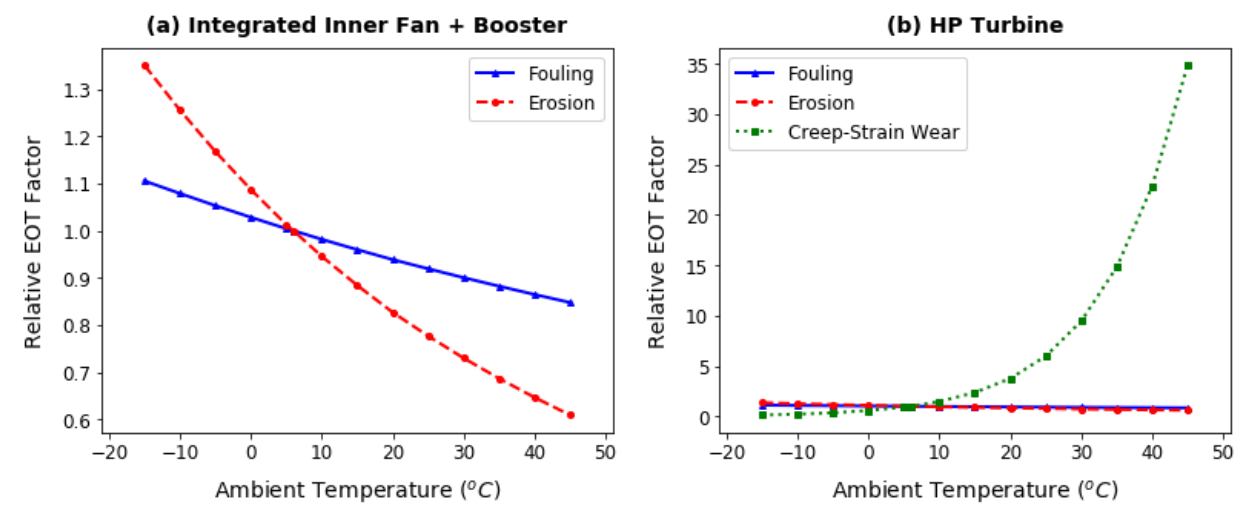

Figure 11 EOT factors for (a) inner fan + booster (b) HP turbine degradation, relative to the reference condition for changing ambient temperature.

\subsection{Changes in Relative Humidity}

The effect of changing ambient relative humidity on core engine performance parameters is presented in Figure 12. Increasing relative humidity from 0 to $100 \%$ only slightly increases the total mass flow rate into the engine because of the higher water vapour content in the air. This produces a marginal reduction in the booster and HP compressor pressure ratios, 
which lowers the power requirement from the HP turbine. The HP turbine operates at a lower TET, although the fuel flow is increased due to the lower burner inlet total pressure. All performance changes observed were below $1 \%$ of their reference values.

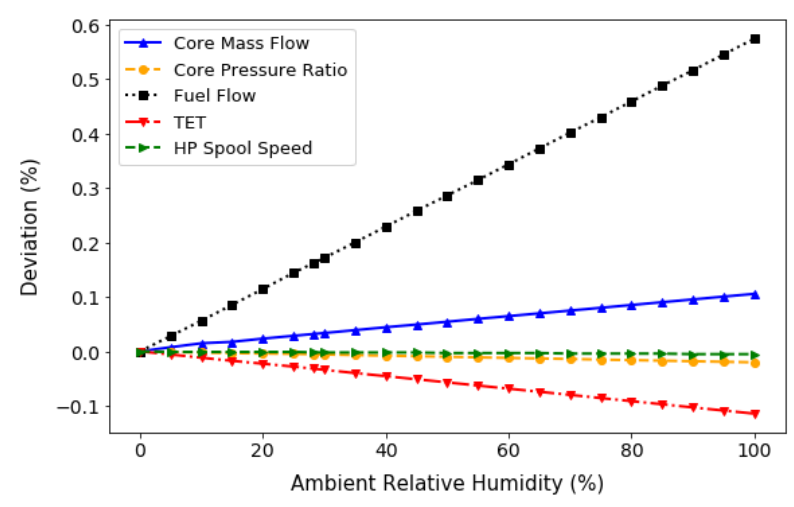

Figure 12 Deviation in performance parameters with changes in ambient temperature.

The effect of humidity on the fouling rate and EOT factor is also dependent on the potential wetting of the foulants and gas path surfaces as the water vapour condenses, which enhances the particle sticking probability or capture ratio [43]. In Figure 13(a), the acceleration of air in the engine intake results in saturated vapour conditions being met at the fan inlet at $R H_{0}=28.35 \%$, i.e. $R H_{2}=100 \%$. This implies that when $R H_{1}=100 \%$, the number and impact of deposited particles in the booster front stages would be twice as much, compared to the reference condition, $\mathrm{RH}_{1}=0 \%$.

The relative humidity does not have a significant effect on the erosion EOT factors in both components and only produces a $4 \%$ reduction in HP turbine creep-strain EOT factor due to the reduced firing temperature.

(a) Integrated Inner Fan + Booster

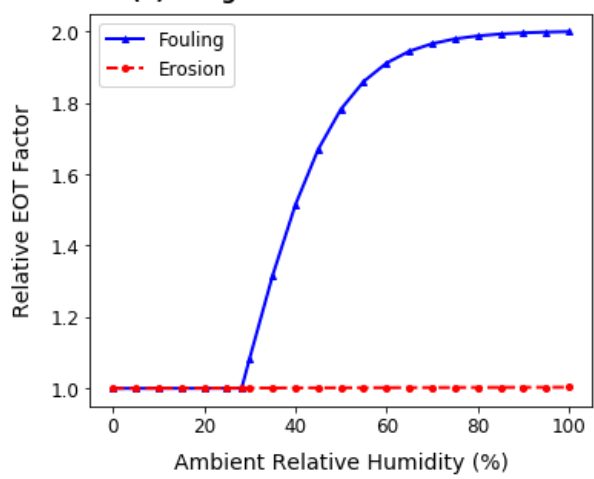

(b) HP Turbine

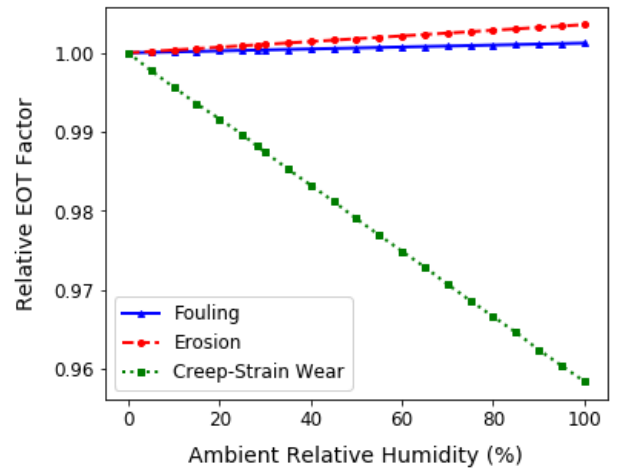

Figure 13 EOT factors for (a) inner fan + booster, and (b) HP turbine degradation, relative to the reference condition for changing ambient relative humidity.

\subsection{Changes in Fan Speed}

With the fan speed decelerated from $100 \%$ to $45 \%$ at the reference ambient condition, the deviations of the simulated engine performance results are shown in Figure 14. Engine part 
speed operation is accompanied by a non-linear reduction in the mass flow rate and overall pressure ratio in the compressor, reduced fuel flow and TET in the burner, and linear drop in HP spool speed.

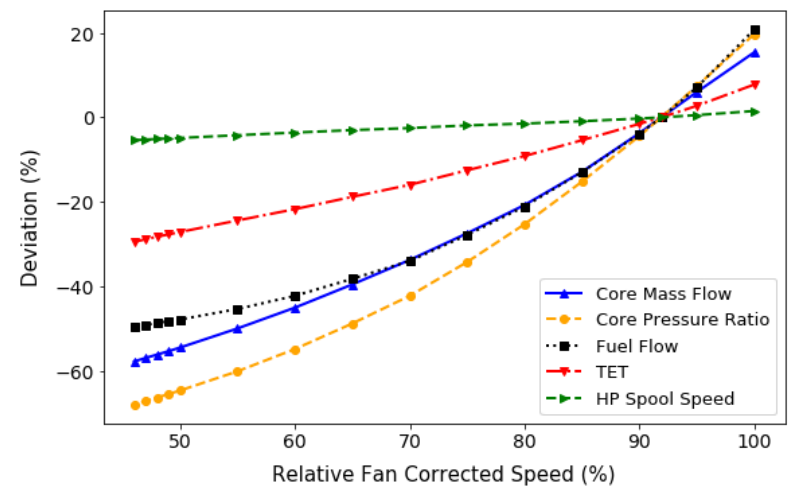

Figure 14 Deviation in performance parameters with changes in fan speed.

The mass flow reduction caused the relative EOT fouling factor to reduce significantly by a factor of 0.73 over the speed range considered, while the drop in relative EOT erosion factor followed a more aggressive path, starting at 1.54 and 0.07 gradient under maximum speed to 0.08 and 0.004 slope at $45 \%$ fan speed as seen in Figure 15(a) and (b). In the HP turbine, the creep strain EOT is insignificant below the reference speed and rapidly increases under over-speed conditions, up to 20 at $100 \%$ fan speed, due to higher TET and HP speed values.
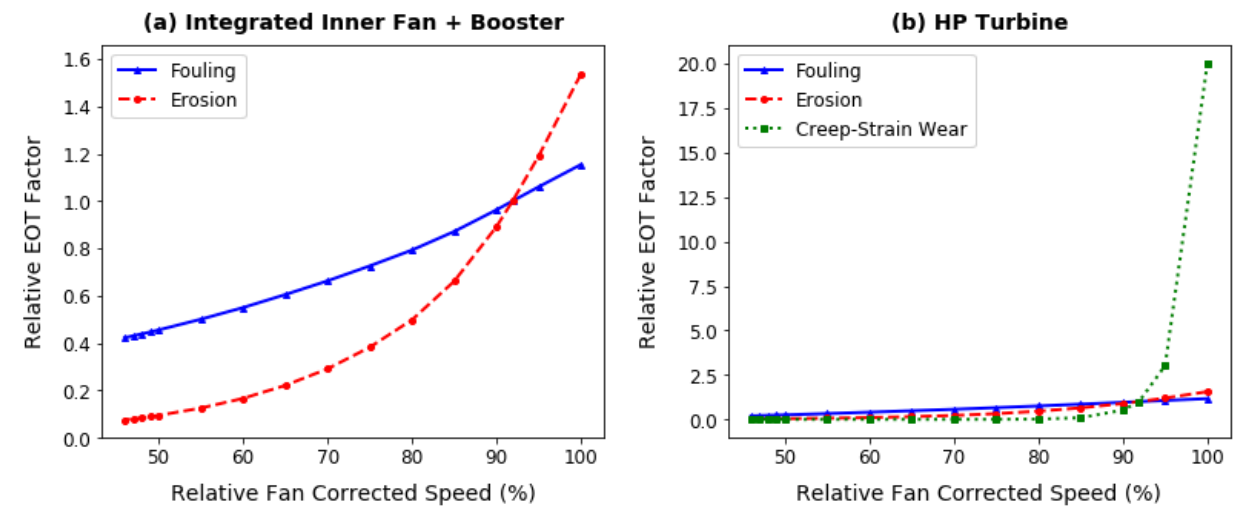

Figure 15 EOT factors for (a) inner fan + booster, and (b) HP turbine degradation, relative to the reference condition for part-speed operation.

\subsection{SINGLE-FLIGHT MISSION EOT ANALYSIS}

\subsection{Flight Description}

A 3.71-hour simulated flight from Kaedi airport, Mauritania to Portela airport, Lisbon was used as a case study to demonstrate the application of the EOT assessment model for a flight cycle where environmental PM measurements are available. This flight trajectory was 
adopted because of the dust particle count and size distribution measurements recorded at low-altitude and under flight conditions as part of the dust characterization survey in the Western Sahara region and Southern Mauritania. The observations were made from particle counters and aerosol spectrometer probes installed on a BAe 146 science aircraft and operated by the Facilities for Airborne Atmospheric Measurements (FAAM) team as part of the FENNEC campaign in June 2012 [44]. Figure 16 shows the altitude, Mach number and engine fan speed readings, with the first 2,500 seconds obtained from the science flight data record.
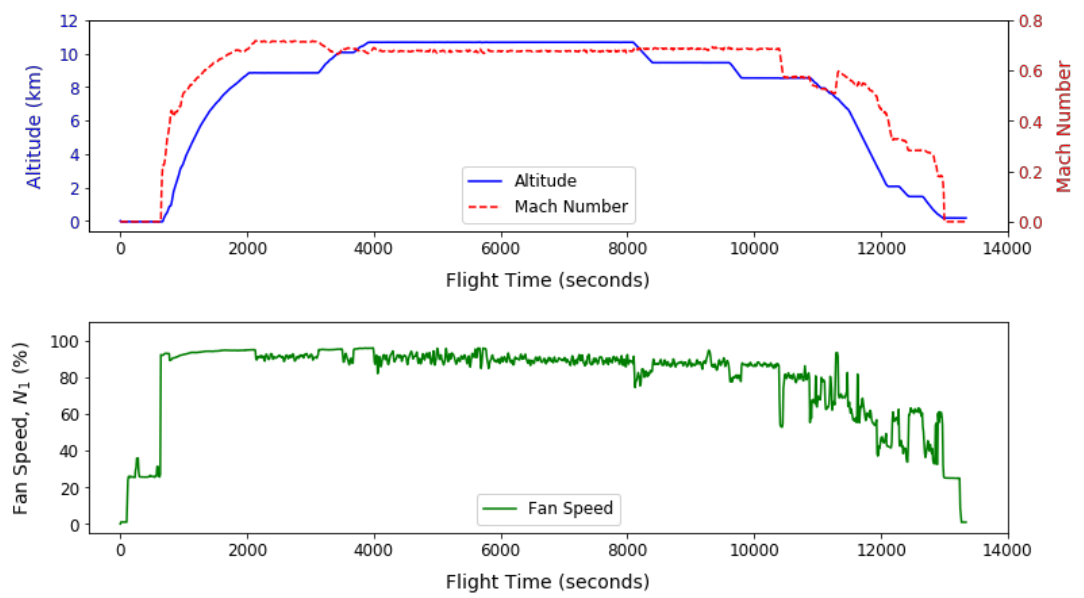

Figure 16 Engine condition and control parameters for the flight cycle.

\subsection{Flight Measurements}

The engine parameters that would have been recorded by the Electronic Centralized Aircraft Monitor (ECAM) were obtained by simulation of the clean engine model performance, under the flight condition settings with $10 \%$ take-off de-rate and a sampling rate of $1 \mathrm{~Hz}$. These parameters are plotted against the left-axes in Figure 17.

As expected, the points of maximum fuel flow, HP spool speed and exhaust gas temperature $\left(\mathrm{T}_{5}\right)$ occurred just at the commencement of take-off, while the cruise phases, characterized by level flight altitude, had relatively stable, steady-state measurements. All sensor perturbations observed in the cruise phase were mainly a result of sensor noise and uncertainty in actual fan speed readings, which were mitigated by exponential-average smoothing and data correction to the reference condition. The critical engine parameters not usually measured by the ECAM were also obtained by the simulation of the engine model performance in PYTHIA over the specified flight profile and are plotted on the right-axes in Figure 17. 

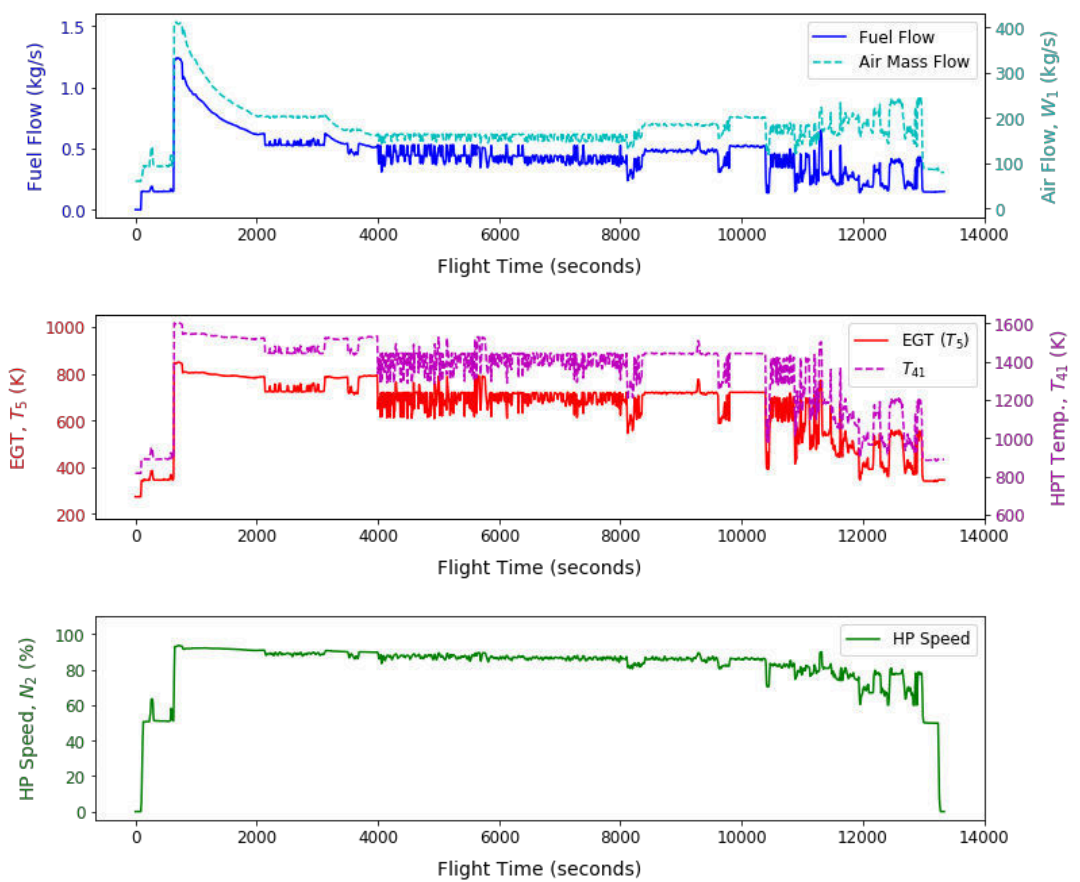

Figure 17 Key engine parameters obtained from ECAM and engine model simulation of the flight profile condition settings.

\subsection{Environmental Particulate Measurements}

The chemical composition over the log-scale size distribution of a Saharan desert sand sample, suspended in air, by volumetric analysis is presented in Figure 18. Three distinct regions $\left(d_{p}<500 \mathrm{~nm}, 500 \leq d_{p}<50 \mu \mathrm{m}, d_{p} \geq 50 \mu \mathrm{m}\right)$ can be observed based on the constitution of sulphates and mineral dust over the aerosol particle diameters [45]. Particles smaller than $0.5 \mu \mathrm{m}$ comprise equal amounts of powdered sulphates and mineral dust; the latter which are oxides, silicates and carbonates. Between $0.35 \mu \mathrm{m}$ and $0.71 \mu \mathrm{m}$, there is a sudden change in composition as the mineral dust dominate and contribute more to the physical texture, while the sulphates constitute only $10 \%$. With increasing particle diameter, the contribution of the sulphates becomes non-existent at $5 \mu \mathrm{m}$, and silicates such as illite and feldspar become the major components. Beyond $50 \mu \mathrm{m}$, quartz becomes the dominant mineral and is manifested as the highly mechanical abrasive properties of desert sand compared to similar-sized samples obtained from other geographic locations. 


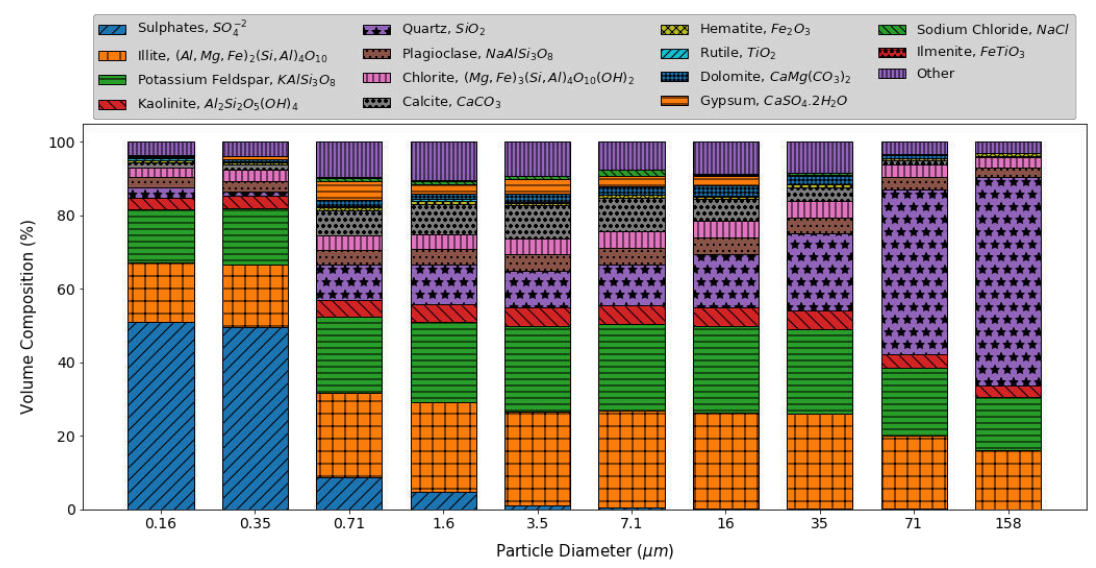

Figure 18 Chemical composition of the desert sand sample.

Figure 19 (a) and (b) show the dust volume concentration per $\mathrm{cm}^{3}$ of air, varying with altitude, with up to $140 \mathrm{~cm}^{-3}$ between $0.1 \mu \mathrm{m}$ and $3 \mu \mathrm{m}$ particle diameters, and up to 3.2 $\mathrm{cm}^{-3}$ between $3 \mu \mathrm{m}$ and $50 \mu \mathrm{m}$ diameter, as measured with a Cloud Droplet Probe (CDP) and Passive Cavity Aerosol Spectrometer Probe (PCASP) respectively [46]. It can be seen that most of the particle concentration falls below $3 \mu \mathrm{m}$ and that environmental dust is an issue for low altitudes and in the harsh desert atmosphere, while at the destination airport, the aerosol probes registered insignificant quantities.

(a) PCSAP readings $(3 \mu m-50 \mu m)$

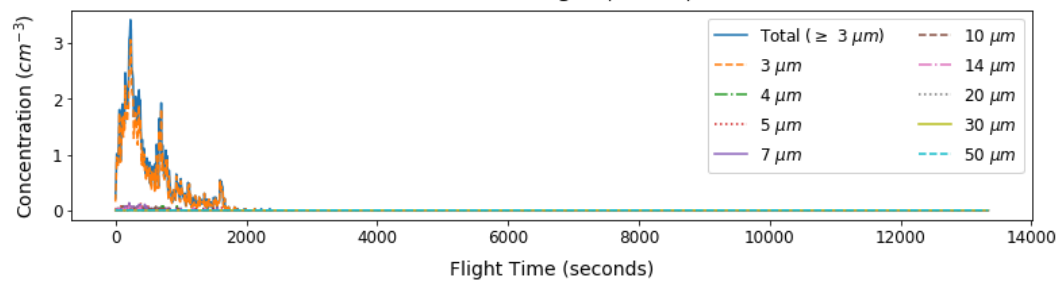

(b) CDP readings $(0.10 \mu m-3 \mu \mathrm{m})$

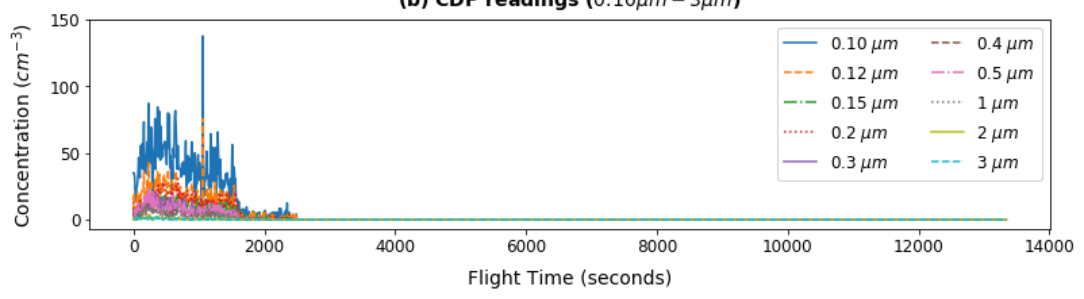

Figure 19 Measured dust concentration in air of various nominal particle sizes over the flight.

The impact of ingested particles on the core engine component deterioration with respect to the exposure time was then quantified using the EOT equations for fouling and erosion as discussed below. 


\section{$5.4 \quad$ Flight EOT}

Using the EOT model equations, the individual and combined EOT factors were estimated and plotted against flight time for the integrated inner fan + booster and HP turbine modules in Figure 20 and Figure 21 respectively. These plots show that for the cruise phase, the calculated EOT was equal to the actual time (EOT factor $\sim 1$ ) as externallyinduced degradation is absent. During take-off and early climb, however, the high dust levels which contribute mainly to fouling resulted in an EOT greater than the actual time, with a maximum fouling EOT factor of 4.45 for the LP compressor and 3.22 for the HP turbine, just before the retraction of the aircraft wing flaps. The erosion EOT factor was close to 1.0 in both cases as a result of low concentration of particles larger than $10 \mu \mathrm{m}$ at any point.

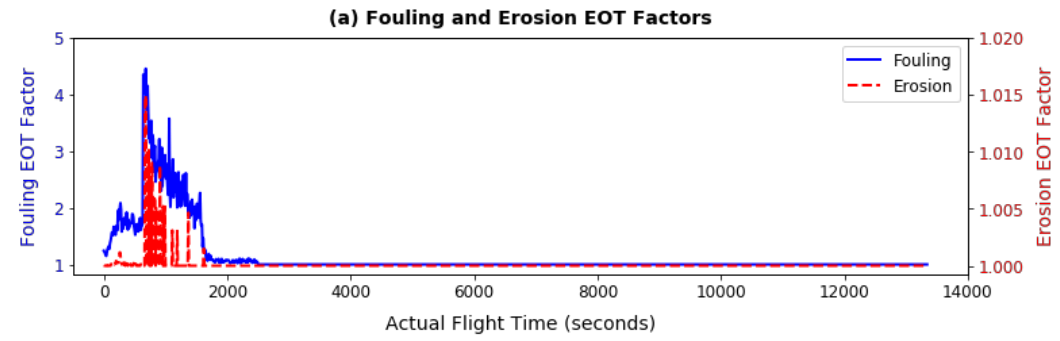

(b) Combined EOT Factors and Flight EOT

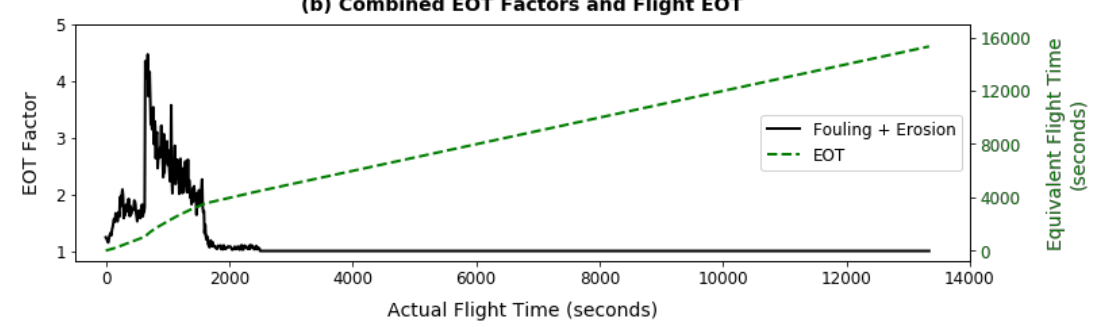

Figure 20 Calculated fouling and erosion EOT over the flight for the inner fan + booster.

In Figure 21, thermo-mechanical strain effects in the HP turbine blades resulted in additional EOT increase of 5.75 at $t=710$ secs due to the combined rotor inlet temperature and HP shaft speed, and therefore the creep strain rate, being higher than the pre-defined reference maximum value. On landing, the absence of significant natural or anthropogenic dust levels meant that no additional degradation occurred in this phase and an EOT of 1 was calculated.

Thus, although the actual flight time was 3.71 hours, the relatively high particulate matter concentration favouring fouling during take-off led to a $14.8 \%$ increase in LP compressor degradation rate, to achieve an EOT of 4.26 hours. Combined with the slightly higher maximum TET above the reference value, a $22.5 \%$ increase in HP turbine degradation rate and $\mathrm{EOT}=4.54$ hours was recorded. It should be noted that this case-study flight scenario is an example of a one-off operation under severe conditions that the aircraft engine would not always be subjected to. 
(a) Fouling, Erosion and Creep-Strain Wear EOT Factors

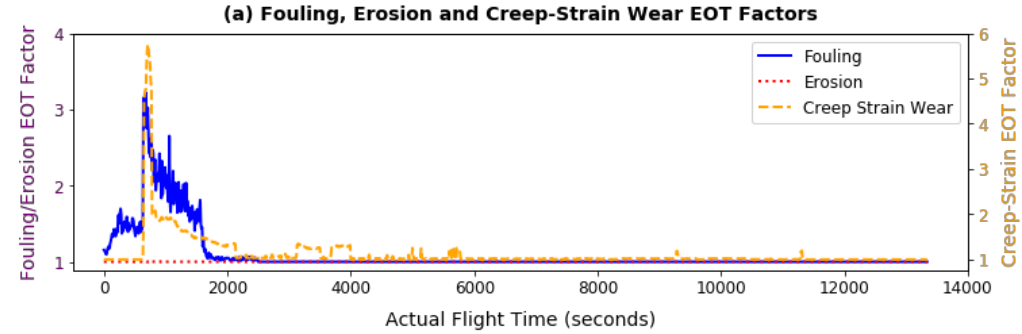

(b) Combined EOT Factors and Flight EOT

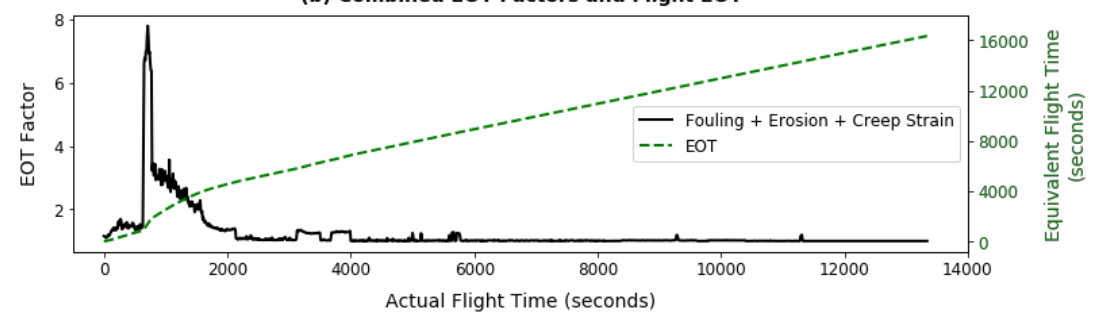

Figure 21 Calculated fouling, erosion and creep-strain EOT over the flight for the HP turbine.

\subsection{MULTIPLE-FLIGHT EOT ANALYSIS}

\subsection{Component Degradation Trend Analysis}

To assess the application of the EOT over a multiple-flight scenario, an independent component analysis based on implanted progressive degradation of the HP turbine only, was done. This is due to the HP turbine being the critical engine module and its susceptibility to all three degradation modes accounted for in the EOT model.

Figure 22(a) and (b) shows the diagnosed HP turbine flow capacity and efficiency indices over actual flight time (blue) for implanted degradation trends, with the diagnosed health parameter values plotted at the end of each simulated 3.71-hour flight. The seeded degradation trend models were obtained by fitting a regression of the form: $\Delta \mathrm{X}=\mathrm{a} \Delta X=$ $a \sqrt{t}+b$ to the diagnosed average HP turbine flow capacity and efficiency deterioration over a 10,000-hour operating period of the Japan Airlines turbofan engine fleet [47]. The coefficients $a$ and $b$ for the flow capacity were found by least-squared fitting to be $(-0.062,100.32)$ and $(-0.031,100.12)$ for the efficiency index. The large scatter observed is mainly attributed to the sensor noise in addition to the different degradation levels attained in each flight due to the different environmental conditions. The red lines in both plots show the same diagnosed component health but plotted against equivalent operating time, which factors in the impact of environmental conditions on the severity of component degradation. It can be seen that while an overall flight time of 10,000 hours was undertaken, the performance deterioration encountered was equivalent to 12,776 hours and 12,744 hours of operation for the flow capacity and efficiency indices respectively, based on the simulated dust concentration and particle size distribution. The component average EOT of 12,760 hours is therefore ascribed to the HP turbine component. The use of the EOT also produces a cleaner trend, as the residual scatter can be attributed to the GPA diagnostic prediction errors arising from the seeding of random sensor noise in generating measurement samples. 
(a) HPT Flow Capacity Index

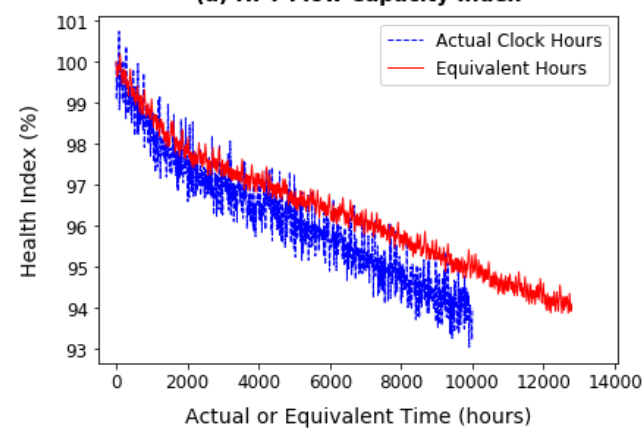

(b) HPT Effiency Index

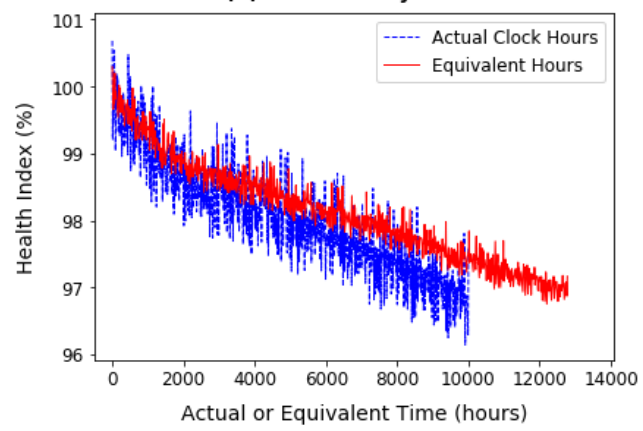

Figure 22 Diagnosed HPT flow capacity and efficiency indices over actual and equivalent hours.

\subsection{RUL Prediction}

The implication of this difference is revealed in predicting the remaining useful life of the component in concern. Figure 23 shows the plot of EOT against actual flight time for the HPT overall health. The nature of the degradation was such that the engine HP turbine was seeded with a normally-distributed concentration of dust particles, about the same size channels and within the limiting values observed in the single-flight case, implanted randomly over its 10,000 hours of operation. Also, at about 4,000 hours, tip rubs of the blade on the casing were seeded, causing the EOT to deviate from the actual time and signifying more severe engine operation than normal. This tip wear process ceased to occur after about 8,000 hours as the tip clearance was stabilized, causing the EOT to exhibit the same gradient as the actual flight time, albeit at a higher absolute value.

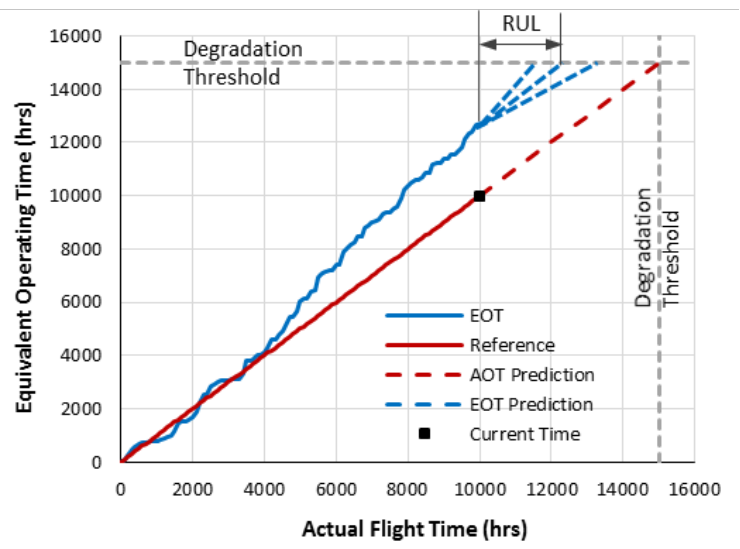

Figure 23 Calculated EOT vs Actual Flight Time for the HP turbine.

For an assumed baseline time-to-overhaul or shop visit interval of 15,000 hours based on the maximum permissible turbine degradation [48], the remaining useful life would be 5,000 hours according to the actual engine flight time. The median remaining useful life for the HPT based on the EOT would, however, be 2,240 hours, which is $45 \%$ of the actual flight-time-based RUL. Applying a 95\% prediction interval to the 10-point moving-average forecast extrapolation, a lower bound (pessimistic) RUL of 1,700 hours is obtained, which is only $34 \%$ of the RUL according to the original engine clock hours. 


\subsection{CONCLUSION}

A method for estimating the degradation equivalent operating time (EOT) to account for the effect of changes in environmental and engine operating conditions on the progression of component degradation has been presented in this paper. The EOT model accounted for 3 degradation modes namely fouling, erosion and performance deterioration effects of HP turbine blade creep-strain leading to tip-rubs.

The effect of ambient, flight and engine thrust setting operating conditions on the predicted EOT factors were assessed through simulation of a turbofan engine performance model under these cases. The results showed that the EOT is able to capture the severity of changes in engine operation when compared to a pre-defined reference condition.

Two cases, based on a single and multiple flight cycles, were investigated to test the capability of the equivalent operating time in providing a better measure of the progression of degradation compared to the actual flight time. For the single flight case, the engine at recorded EOT values in the inner fan + booster and HP turbine components equal to $14.8 \%$ and $22.5 \%$ respectively, more than the actual flight duration mainly due to fouling and higher TETs encountered during take-off. Finally, with randomly-implanted HP turbine degradation over multiple flights in a 10,000-hour operating period, the EOT model revealed a $27.6 \%$ increase in equivalent time, resulting in a $55 \%$ reduction in the calculated time to degradation threshold (i.e. the remaining useful life) when compared to using the actual engine on-wing flight time.

\section{ACKNOWLEDGEMENTS}

The authors would like to thank the Shenyang Engine Design and Research Institute (SEDRI) of the Aircraft Engine Corporation of China (AECC) for providing funding and technical engine data necessary to carry out this research.

\section{REFERENCES}

1. James W., O’Dell P. Derated Climb Performance in Large Civil Aircraft, Article 6. Boeing Performance and Flight Operations Engineering Conference. 2005;

2. Donaldson R., Fischer D., Gough J., Rysz M. Economic Impact of Derated Climb on Large Commercial Engines. 2007 Boeing Performance and Flight Operations Engineering Conference. 2007; : 8.1-8.11.

3. Yong Huang Z., Wagner D., Bathias C., Louis Chaboche J. Cumulative fatigue damage in low cycle fatigue and gigacycle fatigue for low carbon-manganese steel. International Journal of Fatigue. Elsevier Ltd; 2011; 33(2): 115-121. Available at: DOI:10.1016/j.ijfatigue.2010.07.008

4. Janawitz J., Masso J., Childs C. Heavy-Duty Gas Turbine Operating and Maintenance Considerations. Atlanta, GA; 2015. Available at: DOI:GER-3620M

5. Lee J. Total Operating Activities of Gas Turbine Components - Total Equivalent Operating Hours (TEOH). International Gas Turbine and Aeroengine Congress and Exhibition. Indianapolis, Indiana; 1999. pp. 1-4.

6. Zhou D., Wei T., Zhang H., Ma S., Weng S. A Damage Evaluation Model of Turbine Blade for Gas Turbine. Journal of Engineering for Gas Turbines and Power. 2017; 139(September): 1-9. Available at: DOI:10.1115/1.4036060 
7. Abdul Ghafir MF., Li YG., Wang L., Zhang W. Impact Analysis of Aero-engine Performance Parameter Variation on Hot Section's Creep Life Using Creep Factor Approach. American Institute of Aeronautics and Astronautics. 2011; 16(9): 1-12.

8. Eshati S., Abu A., Laskaridis P., Haslam A. Investigation into the Effects of Operating Conditions and Design Parameters on the Creep Life of High Pressure Turbine Blades in a Stationary Gas Turbine Engine. 2011; 15(3): 237-247.

9. Hanumanthan H., Stitt A., Laskaridis P., Singh R. Severity estimation and effect of operational parameters for civil aircraft jet engines. Proceedings of the Institution of Mechanical Engineers, Part G: Journal of Aerospace Engineering. 2012; 226(12): 1544-1561. Available at: DOI:10.1177/0954410011424854

10. Gotoh J., Yasushi H., Shigeo S., Hiraku I. US007065471B2: Method and System for Diagnosing State of Gas Turbine. United States: United States Patent; 2006.

11. Wan A., Gu F., Chen J., Zheng L., Hall P., Ji Y., et al. Prognostics of gas turbine: A condition-based maintenance approach based on multi-environmental time similarity. Mechanical Systems and Signal Processing. 2018; 109: 150-165. Available at: DOI:10.1016/j.ymssp.2018.02.027

12. Seemann R., Langhans S., Schilling T., Gollnick V. Modeling the Life Cycle Cost of Jet Engine Maintenance. Deutscher Luft- und Raumfahrtkongress. 2011; (September): 663-672.

13. Ackert S. Engine Maintenance Concepts for Financiers. Aircraft Monitor. 2011; (2): 30 .

14. Wensky T., Winkler L., Friedrichs J. Environmental Influences on Engine Performance Degradation. Proceedings of ASME Turbo Expo 2010: Power for Land, Sea and Air. Glasgow, UK; 2010. pp. 1-6.

15. Clarkson R., Simpson H. Maximising Airspace Use During Volcanic Eruptions : Matching Engine Durability against Ash Cloud Occurrence. Sto-Mp-Avt-272. 2017; (June): 1-20. Available at: DOI:10.14339/STO-MP-AVT-272

16. Prata AT., Dacre HF., Irvine EA., Mathieu E., Shine KP., Clarkson RJ. Calculating and communicating ensemble-based volcanic ash dosage and concentration risk for aviation. Meteorological Applications. 2019; 26(2): 253-266. Available at: DOI:10.1002/met.1759

17. Zaita A V., Buley G., Karlsons G. Performance Deterioration Modeling in Aircraft Gas Turbine Engines. Journal of Engineering for Gas Turbines and Power. 1998; 120(2): 6. Available at: DOI:10.1115/1.2818128

18. Bojdo N., Filippone A. Effect of Desert Particulate Composition on Helicopter Engine Degradation Rate. 40th European Rotorcraft Forum. Southampton, UK; 2015. Available at: DOI:10.13140/2.1.2959.8086

19. Li YG., Singh R. An Advanced Gas Turbine Gas Path Diagnostic System PYTHIA. VII International Symposium on Air Breathing Engines. Munich, Germany; 2005. pp. 1-13.

20. Meher-homji CB., Focke AB., Wooldridge MB. Fouling of Axial Flow Compressors - Causes, Effcets, Detention, And Control. Proceedings of the Eighteenth Turbomachinery Symposium. 1989; : 55-76.

21. Igie U., Goiricelaya M., Nalianda D. Aero engine compressor fouling effects for short- and long-haul missions. 2016; 230(7): 1312-1324. Available at: DOI:10.1177/0954410015607897

22. Israel R., Rosner DE. Use of a Generalized Stokes Number to Determine the Aerodynamic Capture Efficiency of Non- Stokesian Particles from a Compressible Gas Flow. Aerosol Science and Technology. 1982; 2(1): 45-51. Available at: 


\section{DOI:10.1080/02786828308958612}

23. Bojdo N., Ellis M., Filippone A., Pawley A. Particle-Vane Interaction Probability in Gas Turbine Engines. Journal of Turbomachinery. 2019; 141(September): 1-13. Available at: DOI:10.1115/1.4043953

24. Shrinivas Sreedharan S., Tafti DK. Effect of Blowing Ratio on Early Stage Deposition of Syngas Ash on a Film-Cooled Vane Leading Edge Using Large Eddy Simulations. Journal of Turbomachinery. 2013; 135(6): 061005. Available at: DOI:10.1115/1.4025153

25. El-Batsh H. Modeling Particle Deposition on Compressor and Turbine Blade Surfaces. Vienna University of Technology; 2001.

26. Hamed A., Tabakoff W., Singh D. Modeling of Compressor Performance Deterioration Due to Erosion. International Journal of Rotating Machinery. 1998; 4(4): 243-248.

27. Suman A., Morini M., Aldi N., Casari N., Pinelli M., Spina PR. A Compressor Fouling Review Based on an Historical Survey of ASME Turbo Expo Papers. Journal of Turbomachinery. 2017; 139(4): 041005. Available at: DOI:10.1115/1.4035070

28. Hamed A., Tabakoff W. Turbine Blade Surface Deterioration by Erosion. Journal of Turbomachinery. 2005; 127(3): 445. Available at: DOI:10.1115/1.1860376

29. Diakunchak IS. Performance Deterioration in Industrial Gas Turbines. Journal of Engineering for Gas Turbines and Power. 1992; 114(2): 161. Available at: DOI:10.1115/1.2906565

30. Meher-homji CB., Chaker MA., Motiwala HM. Gas Turbine Performance Deterioration. 30th Turbomachinery Symposium, Texas A\&M University. Texas; 2001. pp. 139-176.

31. Jacobson DH. Gas Turbines. Major Process Equipment Maintenance and Repair. Exxon Co.; 1997. pp. 442-479.

32. Van der Walt JP., Nurick A. Erosion of dust-filtered helicopter turbine engines Part II: Erosion Reduction. Journal of Aircraft. 1995; 32(1): 112-117. Available at: DOI: $10.2514 / 3.56919$

33. Smeltzer CE., Gulden ME., McElmury SS., Compton WA. Mechanisms of Sand and Dust Erosion in Gas Turbine Engines. Fort Eustis, Virginia; 1970. Available at: DOI:AD0876584

34. Kim J., Dunn MG., Baran AJ., Wade DP., Tremba EL. Deposition of Volcanic Materials in the Hot Sections of Two Gas Turbine Engines. Journal of Engineering for Gas Turbines and Power. 1993; 115(3): 641. Available at: DOI:10.1115/1.2906754

35. General Electric Aircraft Engines. HPT Clearance Control - Intelligent Engine Systems - Phase 1. Cincinnati, Ohio; 2005.

36. Abu AO., Eshati S., Laskaridis P., Singh R. Aero-engine turbine blade life assessment using the Neu/Sehitoglu damage model. International Journal of Fatigue. 2014; 61. Available at: DOI:10.1016/j.ijfatigue.2013.11.015

37. Baskharone EA. Principles of Turbomachinery in Air-Breathing Engines. Cambridge, UK: Cambridge University Press; 2006.

38. Li YG. Training Future Engineers on Gas Turbine Gas Path Diagnostics Using Pythia. Proceedings of ASME Turbo Expo 2014: Turbine Technical Conference and Exposition. Dusseldorf, Germany, June 16 - 20, 2014; 2014. pp. 1-10.

39. SAFARAN Snecma - Communications Department. Commercial Aircraft Engines CFM56-7B. Cedex, France; 2011. p. 2. 
40. Li YG., Pilidis P., Newby M a. An adaptation approach for gas turbine design-point performance simulation. Journal of Engineering for Gas Turbines and Power. 2006; 128(4): 789-795. Available at: DOI:10.1115/1.2136369

41. Lo Gatto E., Li YG., Pilidis P. Gas Turbine Off-Design Performance Adaptation Using a Genetic Algorithm. ASME Turbo Expo 2006: Power for Land, Sea, and Air. Barcelona, Spain; 2006.

42. Jasmani MS., Li Y-G., Ariffin Z. Measurement Selections for Multicomponent Gas Path Diagnostics Using Analytical Approach and Measurement Subset Concept. Journal of Engineering for Gas Turbines and Power. 2011; 133(11): 111701. Available at: DOI:10.1115/1.4002348

43. Zaba TB., Lombardi P. Experience in the Operation of Air Filters in Gas Turbine Installations. Brown Boveri Review. Baden, Switzerland; 1984.

44. Facility for Airborne Atmospheric Measurement., Natural Environment Research Council., Met Office. FAAM B702 FENNEC flight, number 4: Airborne atmospheric measurements from core and non-core instrument suites on board the BAE-146 aircraft. NCAS British Atmospheric Data Centre; 2014.

45. Kandler K., Schütz L., Deutscher C., Ebert M., Hofmann H., Jäckel S., et al. Size distribution, mass concentration, chemical and mineralogical composition and derived optical parameters of the boundary layer aerosol at Tinfou, Morocco, during SAMUM 2006. Tellus, Series B: Chemical and Physical Meteorology. 2009; 61(1): 32-50. Available at: DOI:10.1111/j.1600-0889.2008.00385.x

46. Droplet Measurement Technologies. Passive Cavity Aerosol Spectrometer Probe (PCASP-100x) Operator Manual. Boulder, USA; 2011.

47. Sasahara O. JT9D Engine/Module Performance Detrioration Results from Back to Back Testing. International Symposium on Air Breathing Engines. Beijing, China; 1985. pp. 528-535.

48. Aircraft Commerce. Aircraft Owner's \& Operator's Guide: B737NG family. Aircraft Commerce. 2010; : 3-30. 
2020-01-09

\section{Assessment of degradation equivalent operating time for aircraft gas turbine engines}

Alozie, Ogechukwu

Cambridge University Press

Alozie O, Li YG, Diakostefanis M, et al., (2020) Assessment of degradation equivalent operating time for aircraft gas turbine engines. The Aeronautical Journal, Volume 124, Issue 1274, April 2020, pp. 549-580

https://doi.org/10.1017/aer.2019.153

Downloaded from Cranfield Library Services E-Repository 